MARIANO LAMBEA

\title{
EDICIÓN FACSÍMIL DEL APOSENTO ANTI-CRÍTICO DE JUAN FRANCISCO DE COROMINAS
}

Separata de la

REVISTA DE MUSICOLOGÍA

Volumen XXIV, $\mathrm{n}^{\text {os }} 1-2$

Enero - Diciembre de 2001

MADRID

2001 


\section{EDICIÓN FACSÍMIL DEL APOSENTO ANTI-CRÍTICO DE JUAN FRANCISCO DE COROMINAS*}

Mariano LAMBEA

\section{Introducción}

El deseo por conocer nuestro pasado musical, las obras y escritos de nuestros compositores, intérpretes y teóricos, así como el interés por comprender mejor la historia de nuestra música, nos exige una postura de acercamiento y contacto directo con las fuentes de primera mano. El Aposento anti-crítico desde donde se ve representar la gran comedia que, en su Teatro Crítico, regaló al pueblo el RR. P. M. Feijoo contra la música moderna y uso de los violines en los templos (1726) de Juan Francisco de Corominas es conocido sobradamente por la musicología española, tanto como documento histórico, estético y doctrinal interesante para el conocimiento de nuestra historia musical, como por hallarse inmerso de pleno en una de las polémicas musicales más encendidas del siglo XVIII. Como se sabe, el folleto es una especie de carta abierta, escrita con el propósito de defender la música moderna y el uso de los violines en el templo ante los ataques y opiniones contrarias vertidas por el polígrafo auriense padre Benito Jerónimo Feijoo (1676-1764) en su discurso XIV titulado "Música de los Templos", publicado en 1726, en el primer tomo de su Teatro Crítico Universal ${ }^{1}$. La fuerte polémica que suscitó la publicación del ensayo mu-

- Agradecemos a la Biblioteca Nacional (Madrid) la autorización concedida para la publicación del Aposento de Corominas. También hacemos constar nuestro agradecimiento a Ana $\mathrm{Zu}-$ gasti por la valiosa ayuda prestada en la consulta de la primera edición del Teatro Crítico Universal, en la mencionada biblioteca.

${ }^{1}$ Los ejemplares conservados de la primera edición de esta obra se hallan en Madrid, Salamanca y Bilbao, según refiere AGUILAR PIÑAL, Francisco: Bibliografía de autores españoles del siglo XVIII, Madrid, Consejo Superior de Investigaciones Científicas, tomo III, 1984, p. 260b. Para 
sical del sabio benedictino ha sido debidamente estudiada ya por la musicología española, ${ }^{2}$ y, en consecuencia, no vamos a retomar aquí el hilo de este tema ni a redundar en lo ya investigado. Tampoco entraremos a valorar la importancia del opúsculo de Corominas ni su significación en el contexto de la polémica misma. Todo esto está ya hecho -y, además, magníficamente- y damos al lector por avisado en la materia.

Lo que no está hecho, sin embargo, es la edición en facsímile del folleto, y éste es, precisamente, el propósito de nuestro trabajo. Con ello cumpliremos los objetivos que nos habíamos propuesto al emprender esta tarea, los cuales no son otros más que satisfacer el interés musicológico y conseguir la amplia difusión del Aposento, puesto que disponemos prácticamente de un único ejemplar de este documento para su consulta pública. ${ }^{3}$ Ya lo decía Martín Moreno cuando transcribía este tipo de escritos: "Los textos seleccionados son, a veces, extensos, pero lo he preferido así por el interés de los mismos y la dificultad que representa su consecución"

Aunque la edición facsimilar se justifica por sí misma, creemos oportuno incluir algunas notas críticas o aclaratorias por sí son necesarias para la mejor comprensión del escrito de Corominas, sin que ello nos lleve a la edición crítica, es decir, 'filológicamente correcta', lo cual sería tarea

nuestro trabajo hemos utilizado la segunda edición, realizada un año después de la primera y uno de cuyos ejemplares se conserva en la Biblioteca de Catalunya. Es la siguiente, FEYJOO, Benito Gerónimo: Teatro Crítico Universal, Madrid, Imprenta de Lorenzo Francisco Mojados, 1727, tomo primero, segunda impresión. Concretamente nos interesa el discurso XIV titulado "Música de los templos", dividido en XII capítulos que contienen 52 párrafos debidamente numerados, y que se halla entre las pp. 288-313.

${ }^{2}$ Véase LEÓN TELLO, Francisco José: La teoría española de la música en los siglos XVII y XVIII, Madrid, Consejo Superior de Investigaciones Científicas, 1974, pp. 173-190. Especialmente, también, los trabajos de MARTÍN MORENO, Antonio: El Padre Feijoo y las ideologías musicales del XVIII en España, Orense, Instituto de Estudios Orensanos "Padre Feijoo", 1976, pp. 187-266; Ídem: "El P. Feijoo y la estética musical del siglo XVIII". En: II Simposio sobre el padre Feijoo y su siglo, Oviedo, Centro de Estudios del Siglo XVIII, Cátedra Feijoo, 1981, pp. 423-441; e Historia de la Música Española, 4. Siglo XVIII, Madrid, Alianza Editorial, 1985, pp. 419-425. Y, por último, los artículos de SANHUESA FONSECA, María: "Feijoo y Montenegro, Benito Jerónimo". En: Diccionario de la Música Española e Hispanoamericana. Dir. Emilio Casares Rodicio, Madrid, Sociedad General de Autores y Editores, vol. 5, 1999, pp. 8-13; y "Corominas, Juan Francisco de": Ibídem, vol. 4, 1999, pp. 17-18.

${ }^{3}$ Otro ejemplar -no tan bien conservado como el de la Biblioteca Nacional-se custodia en la sección de Reserva de la Biblioteca del Departamento de Musicología de la Institución Milá y Fontanals del CSIC (Barcelona). El hecho de que este ejemplar no se halle registrado en la Bibliografía... de Aguilar Piñal se debe a su posterior catalogación en los Catálogos Informatizados de la Red de Bibliotecas del CSIC (CIRBIC).

${ }^{4}$ MARTÍN MORENO: El Padre Feijoo y las ideologías musicales..., p. 191. 
para un filólogo. Nuestro interés, como es lógico, es más musical que literario. Siempre que sea posible intentaremos dar algunas mínimas referencias sobre algunos vocablos o términos de la lexicografía musical que nos parezcan confusos, así como sobre determinados nombres propios de músicos, teóricos, artistas, etc., ya sea porque su grafía se preste a confusión o porque no sean suficientemente conocidos. Obviaremos, en este sentido, aquellos que, a nuestro juicio, hayan conseguido un puesto en la celebridad. Ciertamente la pluma del violinista Corominas, además de estar adornada de los ribetes de literato característicos de la época, rezuma causticidad y sutileza, sal e ironía a partes iguales, todo lo cual unido a una sintaxis y una puntuación a la que no estamos acostumbrados, hace posible que su texto nos resulte, en pasajes determinados, un tanto críptico y difícil de entender. Por otra parte, esperamos no abundar en exceso en las interpolaciones y apostillas que, con tan buen criterio, escribieran León Tello y Martín Moreno en su momento, y más recientemente María Sanhuesa, en los trabajos que hemos citado ya de estos tres musicólogos. La lectura del Aposento ha de simultanearse con la de las obras de Feijoo que traten sobre la música, especialmente, con el discurso XIV, ya citado, del cual transcribimos los capítulos o párrafos a los que hace referencia Corominas, aunque reconocemos que lo ideal y práctico hubiera sido reproducir íntegramente el discurso feijoano, pero la falta de espacio nos lo ha impedido.

\section{Fuente y descripción}

El ejemplar que sirve de base a la presente edición facsimilar pertenece a la edición de 1726 impresa en Salamanca, en la Imprenta de la Santa Cruz, y se conserva en la Biblioteca Nacional (Madrid), bajo la signatura M. $3602 / 22 .{ }^{5}$

El folleto fue descrito por Anglés y Subirá. ${ }^{6}$ Por nuestra parte sintetizamos dicha descripción y precisamos algunos aspectos referentes a la foliación y la paginación. La foliación es para las páginas que anteceden al cuerpo de la obra, que están señaladas como "A2" y "A3", siendo su contenido y distribución de la siguiente manera:

\footnotetext{
${ }^{5}$ Véase ANGLÉS, Higinio y SUBIRÁ, José: Catálogo Musical de la Biblioteca Nacional de Madrid, Barcelona, Consejo Superior de Investigaciones Científicas, 1951, vol. III, pp. 329-330. Véase también AGUILAR PIÑAL: Op. cit., tomo II, 1983, p. 575a, registrado con la signatura V. E. Caja 301 (22).

${ }^{6}$ ANGLÉS y SUBIRÁ: Op. cit., pp. 329-330.
} 
[A1r]: Título y pie de imprenta sin año, pero "añadido por Barbieri, a pluma: $1726^{\prime \prime}{ }^{7}$

[A1v]: En blanco.

A2r: Dedicatoria al Sr. D. Diego Fernando de Contreras.

A2v: Continúa la dedicatoria.

A3r: Termina la dedicatoria y consta la fecha "diciembre 14 de 1726".

A3v: Censura de fecha "diciembre 11 de 1726" y Licencia del Ordinario de fecha "10 de diciembre de 1726 años".

La paginación es para el cuerpo de la obra, aunque a la primera página se la denomina como "Fol. 1" y la quinta está sin numerar.

\section{Nota bene}

En las transcripciones de fragmentos del Aposento, así como en las del discurso "Música de los Templos", del Diccionario de Autoridades ${ }^{8}$ (de ahora en adelante, $A$ ut.) y de otros tratados que hemos manejado, modernizamos la ortografía, la puntuación y el uso de mayúsculas. Respetamos en todos los casos los fragmentos en cursiva. Las notas críticas o aclaratorias hacen referencia al folio (fol.), página o páginas (pág. o págs.) y a la línea o líneas (lín. o líns.) del Aposento.

\section{Notas críticas o aclaratorias}

A2r, lín. 9: "19 de octubre de este año [=1726]" podría ser la fecha en la que Corominas tuvo su primer contacto con la obra de Feijoo. Dice Martín Moreno: "A pesar de que la primera edición del Teatro lleva en una de las licencias fecha de 5 de febrero de 1727, parece que el tomo en cuestión se vendió ya en septiembre de 1726, como confirman las fechas de las aprobaciones, tasas, licencias, etc., [las cuales van desde el 27 de junio hasta el 25 de agosto de 1726] de los folletos que aparecieron en su contra el año de 1726. Este mismo año nos encontramos ya con varios importantes opúsculos rebatiendo las ideas expuestas en el Discurso XIV. No esperaron mucho los músicos, que se sintieron ofendidos en su honrilla profesional". 9

\footnotetext{
${ }^{7}$ Ibídem, p. 329.

${ }^{8}$ Diccionario de Autoridades, Madrid, Editorial Gredos, 1963.

${ }^{9}$ MARTÍN MORENO, Antonio: El Padre Feijoo y las ideologias musicales..., p. 201.
} 
A3r, última lín.: La laguna que se observa, precisamente en el apellido del autor, es privativa de este ejemplar. En el que se conserva en el Departamento de Musicología del CSIC el apellido Corominas aparece claramente.

Fol. 1, lín. 5-8: "de que atenderá quejas, y mas ${ }^{10}$ de músicos ofendidos no puede acarrearle más gusto que una terrible zarabanda de dicterios". Lógicamente ya intuía Feijoo las críticas, y las predecía con estas palabras escritas en el último párrafo de su prólogo al lector: "estoy esperando muchas impugnaciones, especialmente sobre dos o tres discursos de este libro; y aun algunos me previenen que cargarán sobre mí injurias y dicterios". Seguramente uno de esos discursos sería el XIV, el de la "Música de los Templos".

Pág. 2, penúltima y última lín.: Se lee con dificultad "si havían estudiado".

Pág. 2, última lín.: "alguna Paulina en la Nunciatura". "Paulina", en Aut., es "la carta o edicto de excomunión que se expide en el Tribunal de la Nunciatura u otro pontificio. Llamóse así porque, en tiempo del Papa Paulo III, tomó fuerza la costumbre de estos edictos". En una segunda acepción Aut. escribe: "Por extensión se dice por el conjunto de palabras injuriosas con que uno zahiere a otro".

Págs. 2-4, desde la lín. 10 de la pág. 2: "Una tarde de las pasadas", hasta la lín. 5 de la pág. 4: "Teatro Crítico Universal", relata Corominas su encuentro y conversación con "amigos y compañeros" que le informan de viva voz acerca de la condena de la música moderna y del uso del violín en la iglesia, hasta que le "pusieron un libro en la mano que decía: Teatro Crítico Universal".

Pág. 3, primera y segunda líns.: "se ensayaban a recitarla por las reglas del Tribunal de Toledo". Quizá sea una expresión proverbial que Corominas utiliza con referencia a la hegemonía económica, cultural, artística, política y legislativa de que había gozado Toledo tradicionalmente, $\mathrm{y}$, sobre todo, en tiempos de Carlos V. Téngase en cuenta que los Reyes Católicos convocaron las Cortes de Toledo en 1480 para reorganizar el consejo real, como cuerpo consultivo permanente y tribunal supremo de justicia.

Pág. 3, última lín.: "Breve de Nuestro Santísimo Padre". "Breve", en Aut., es "el Buleto Apostólico concedido por el Sumo Pontífice, o por su Legado adlátere. Llamóse breve porque se escribe y despacha sin las formalidades jurídicas".

\footnotetext{
${ }^{10}$ Transcribimos como conjunción adversativa en lugar de adverbio comparativo.
} 
Pág. 4, líns. 6-7: “¿En manos de críticos ha dado nuestra música?” Clara alusión irónica de Corominas hacia el epíteto "crítico" en el título de la obra feijoana. La ironía persiste en todo el párrafo.

Pág. 4, última lín.: "el parrafito de violines". Se refiere Corominas, no sin sorna, concretamente al párrafo 43 del capítulo XI del discurso feijoano, pero creo que, por su interés, no está por demás transcribir el párrafo que le antecede y el que le sigue:

"42. Por la misma razón estoy mal con la introducción de los violines en las iglesias. Santo Thomás, en el lugar citado arriba, quiere que ningún instrumento músico se admita en el templo por la razón de que estorba a la devoción aquella delectación sensible que ocasiona la música instrumental. Pero esta razón es difícil de entender, habiendo dicho el Santo que la delectación que se percibe en el canto induce a devoción a los espíritus flacos; y no parece que hay disparidad de una a otra: porque, si se dice que la significación de la letra que se canta, ofreciendo a la memoria las cosas divinas, hace que la delectación en el canto sirva como de vehículo que lleve el corazón hacia ellas, lo mismo sucederá en la delectación de el instrumento que acompaña la letra y el canto. Añádese a esto que el Santo, en el mismo lugar, aprueba el uso de los instrumentos músicos en la sinagoga, por la razón de que aquel pueblo, como duro y carnal, convenía que, con este medio, se provocase a la piedad. Luego, por lo menos, para semejantes genios convienen en la Iglesia los instrumentos músicos. Y, por consiguiente, siendo de este jaez muchísimos de los que concurren a la Iglesia en estos tiempos, siempre serán de grande utilidad los instrumentos. Fuera de que no puedo entender cómo la delectación sensible que ocasiona la música instrumental induzca a devoción a los que, por su dureza, están menos dispuestos para ella, y la impida en los que tienen el corazón más apto para el culto divino.

43. Conozco, y confieso, que es mucho más fácil que yo no entienda a Santo Thomás que no que el Santo dejase de decir muy bien. Mas, en fin, la práctica universal de toda la Iglesia autoriza el uso de los instrumentos. El caso está en la elección de ellos. Y por mí digo que los violines son improprios en aquel Sagrado Teatro. Sus chillidos, aunque harmoniosos, son chillidos, y excitan una viveza, como pueril, en nuestros espíritus, muy distante de aquella atención decorosa que se debe a la majestad de los Misterios; especialmente en este tiempo que los que componen para violines ponen estudio en hacer las composiciones tan subidas que el ejecutor vaya a dar en el puente con los dedos.

44. Otros instrumentos hay respectosos y graves como la harpa, el violón, la espineta, sin que sea inconveniente de alguna monta que falten tiples en la música instrumental. Antes, con eso, será más majestuosa y 
seria, que es lo que en el templo se necesita. El órgano es un instrumento admirable, o un compuesto de muchos instrumentos. Es verdad que los organistas hacen de él, cuando quieren, gaita y tamboril, y quieren muchas veces". ${ }^{11}$

[Pág. 5] ${ }^{12}$, líns. 6-7: "sea mucha hermosura por de fuera y un Antón Martín por de dentro". Puede tratarse de un refrán o de una expresión proverbial. Antón Martín es un personaje popular muy conocido. Por otra parte, Antón y Martín, especialmente este último, son nombres de santos que suelen aparecer en varias locuciones.

Pág. 7, líns. 8-13: "en esto de latines tengo poquísimos alcances, porque son los míos como los rayos de la luna, per participationem. Hánmelos pegado las losas que piso y los postes que venero en los patios de esta Athenas". En efecto, la luna participa de los rayos del sol, como el propio Corominas participaba del conocimiento del latín, es decir, simplemente a través de su contacto con los patios de la Universidad de Salamanca ("esta Athenas"). Más adelante, en la pág. 19, líns. 21-23, vuelve a hacer referencia el violinista de sus escasos conocimientos de latín con estas palabras: "Yo citara los versecillos latinos que lo prueban, pero músico me soy y nada más". Sabido es, por otra parte, que Feijoo, al igual que tantos otros escritores y tratadistas, interpolaba frases latinas en su texto como principio de autoridad para reforzar sus propias opiniones. ${ }^{13}$

Pág. 7, fragmento del último párrafo: "Convengo desde luego en aquel antiquísimo uso de la música para las aras sólo". Muestra aquí Corominas su afinidad con el párrafo 4 del capítulo II del discurso feijoano:

"Así se dividió en aquellos retirados siglos la música entre el templo y el teatro sirviendo promiscuamente a la veneración de las aras y a la corrupción de las costumbres. Pero aunque ésta fue una relajación lamentable, no fue la mayor que padeció este arte nobilísimo: porque ésta se guardaba para nuestro tiempo. Los griegos dividieron la música que, antes, como era razón, se empleaba toda en el culto de la deidad, distribuyéndola entre las solemnidades religiosas y las representaciones scénicas, pero conservando en el templo la que era propria de el templo y dando al teatro la que era propria de el teatro. ¿Y en estos últimos tiempos, qué se ha

\footnotetext{
${ }^{11}$ FEYJOO: Op. cit., pp. 308-310.

${ }^{12}$ El número 5 falta también en el ejemplar del Departamento de Musicología del CSIC.

${ }^{13}$ En este sentido véase el interesante prólogo de Antonio FONTÁN al libro de SÁNCHEZ DONCEL, Gregorio: Diccionario de latinismos y frases latinas, Madrid, Editorial Noesis, 1997.
} 
hecho? No sólo se conservó en el teatro la música de el teatro, mas también la música propria de el teatro se trasladó al templo". ${ }^{14}$

Pág. 8, lín. 2: "números". "Número", en Aut., séptima acepción, "significa también la determinada medida proporcional o cadencia que hace harmoniosos los períodos músicos, y los de la poesía y retórica, y por eso agradables y gustosos al oído". Incluimos las referencias que daba Pedro Cerone (ca. 1566-1625) ante un concepto que, ciertamente, se nos muestra ambiguo y confuso: "De modo que propriamente por teórico se ha de entender aquel que, doctrinal y scientíficamente, de la música sabe hablar y discurrir, diciendo de la composición de los números sonoros y disonoros, del modo de proporcionarlos, de su oposición y comparación, de las agregaciones harmoniales, de las disposiciones consonantes, y finalmente de todas aquellas cosas que tracta el teórico en la consideración de la simple sciencia, llamada propriamente especulativa" ${ }^{15}$ Y más adelante añade: "Digo que los antiguos llamaban músicos a los poetas, porque, bien considerado, las rimas y poesías otra cosa no son que versos; los versos: cadencias o cláusulas; las cláusulas: consonancias; las consonancias: números sonoros; los números sonoros: harmonía; y la harmonía: música". ${ }^{16}$

Pág. 8, líns. 20-23: "porque también se oyen en las Iglesias aquellos airecillos que fueron, la noche antes, pasto a la atención de un sarao ${ }^{\prime \prime} .{ }^{17} \mathrm{Se}$ refiere aquí Corominas al párrafo 5 del capítulo II del discurso feijoano, que dice así:

"Las cantadas que ahora se oyen en las Iglesias son, en cuanto a la forma, las mismas que resuenan en las tablas. Todas se componen de menuetes, recitados, arietas, alegros y, a lo último, se pone aquello que llaman Grave; pero de eso muy poco, porque no fastidie. ¿Qué es esto? ¿En el templo no debiera ser toda la música grave? ¿No debiera ser toda la composición apropriada para infundir gravedad, devoción y modestia? Lo mismo sucede en los instrumentos. Ese aire de canarios, ${ }^{18} \tan$ dominante en el gusto de los modernos y estendido en tantas gigas que apenas hay sonata

${ }^{14}$ FEYJOO: Op. cit., pp. 289-290.

${ }^{15}$ CERONE, Pedro: El Melopeo, tractado de música teórica y prática, Nápoles, Iuan Bautista Gargano y Lucrecio Nucci, 1613, p. 219. Hay edición facsímil a cargo de F. Alberto Gallo, en Forni Editore Bologna, 1969, 2 vols.

${ }^{16}$ Ibidem, p. 220.

17 "Sarao", en Aut., es la "junta de personas de estimación y jerarquía para festejarse con instrumentos y bailes cortesanos. Tómase por el mismo baile o danza entre muchos".

18 "Canario", en Aut., segunda acepción, es un "tañido músico de cuatro compases que se danza haciendo el son con los pies, con violentos y cortos movimientos". 
que no tenga alguna, ¿qué hará en los ánimos, sino excitar en la imaginación pastoriles tripudios? ${ }^{19}$. El que oye en el órgano el mismo menuet que oyó en el sarao, ¿qué ha de hacer, sino acordarse de la dama con quien danzó la noche antecedente? De esta suerte, la música, que había de arrebatar el espíritu de el asistente desde el templo terreno al celestial, le traslada de la Iglesia al festín. Y si el que oye, o por temperamento, o por hábito, está mal dispuesto, no parará ahí la imaginación". ${ }^{20}$

Pág. 9, líns. 12-15: "el crítico sin tacha, aquél de los sesos en la mollera y la cabeza sobre los hombros: el gran Lorenzo Gracián". Este crítico no es otro que el famoso escritor Baltasar Gracián (1601-1658), que utilizó como seudónimo el nombre de uno de sus hermanos para publicar diversas obras, entre ellas la segunda y tercera parte de uno de sus libros emblemáticos: El criticón (1653-1657). El fragmento que sigue a la lín. 15 hasta el final de página hace referencia, precisamente, a esa visión alegórica de la vida humana que se trasluce en esta obra del célebre jesuita.

Pág. 9, antepenúltima lín.: "hoinbres". ¿Estará por hombres?

Pág. 10, líns. 11-12: "y en manos anda el pandero". Refrán recogido en la voz "Pandero" de Aut.: "En manos está el pandero que le sabrá bien tocar. Refr[án] con que se da a entender que se puede fiar algún negocio u otra cosa de alguna persona por la seguridad que se tiene de su habilidad y capacidad, y que se conseguirá con todo acierto". Ataque de Corominas culpando a Feijoo de su obsesión en poner nombres a todo e invitándole a que abandone esa postura en favor de los músicos profesionales que, a la postre, son los auténticamente cualificados para ello.

Pág. 11, primera lín.: "vagio". ¿Estará por vacío?

Pág. 11, líns. 18-19: "y cita V. R. en el párrafo nono". Corominas quiere decir "capítulo" en lugar de "párrafo". A pesar de su extensión, creemos oportuno citar este capítulo IX íntegro, con sus seis párrafos, del discurso de Feijoo:

"33. Lo que se ha dicho hasta aquí de el desorden de la música de los templos no comprende sólo las cantadas en lengua vulgar, mas, también, psalmos, misas, lamentaciones y otras partes de el Oficio Divino, porque en todo se ha entrado la moda. En lamentaciones impresas he visto aquellas

19 "Tripudio", en Aut., es una "danza o baile. Es del latino tripudium, pero tiene poco uso [...]. Comprende toda suerte de bailes, así antiguos como modernos, entrando en ellos los tripudios y fiestas que hacía la gente loca del mundo".

${ }^{20}$ FEYJOO: Op. cit., p. 290. 
mudanzas de aires, señaladas con sus nombres, que se estilan en las cantadas. Aquí se leía Grave, allí Airoso, acullá Recitado. ¿Qué aún en una lamentación no puede ser todo grave? ¿Y es menester que entren los airecillos de las comedias en la representación de los más tristes misterios? Si en el cielo cupiera llanto, lloraría de nuevo Jeremías al ver aplicar tal música a sus trenos. ${ }^{21} i$ Es posible que en aquellas sagradas quejas, donde cada letra es un gemido, donde, según varios sentidos, se lamentan, ya la ruina de Jerusalén por los caldeos, ya el estrago de el mundo por los pecados, ya la aflicción de la Iglesia militante en las persecuciones, ya en fin la angustia de nuestro Redemptor en sus martirios, se han de oír Airosos y Recitados? ¿En el alfabeto de los penitentes, como llaman algunos expositores ${ }^{22}$ a los trenos de Jeremías, han de sonar los aires de festines y serenatas? Con cuanta más razón se podía exclamar aquí con la censura de Séneca contra Ovidio, porque, en la descripción de un objeto tan trágico como el Diluvio de Deucalión ${ }^{23}$ introdujo un verso tanto cuanto ameno: Non est res satis sobria lascivire devorato orbe terrarum. No sonó tan mal la cítara de Nerón cuando estaba ardiendo Roma, como suena la harmonía de los bailes cuando se están representando tan lúgubres misterios.

34. Y sobre delinquirse en esto contra las reglas de la razón se peca también contra las leyes de la música, las cuales prescriben que el canto sea apropriado a la significación de la letra: $y$, así, donde la letra toda es grave y triste, grave y triste debe ser todo el canto.

35. Es verdad que, contra esta regla, que es una de las más cardinales, pecan muy frecuentemente los músicos en todo género de composiciones; unos por defecto y otros por exceso. Por defecto, aquellos que forman la música sin atención alguna al genio de la letra; pero, en tan grosera falta apenas caen, sino aquellos, que no siendo verdaderamente compositores, no hacen otra cosa que tejer retazos de sonatas o coser arrapiezos de las composiciones de otros músicos.

36. Por exceso yerran los que, observando con pueril escrúpulo la letra, arreglan el canto a lo que significa cada dicción de por sí, y no al intento

21 "Threno", en Aut., es una "lamentación fúnebre por alguna calamidad u desgracia [...]; y por antonomasia se toma por las del Profeta Jeremías".

22 "Expositor", en Aut., es "el que interpreta, expone y declara lo que es obscuro y difícil de entender." Por antonomasia, el que expone o explica la Sagrada Escritura, o un texto jurídico.

${ }^{23}$ Deucalión, hijo de Prometeo, construyó un arca para salvarse, junto con su mujer Pirra, del diluvio con el que Zeus castigó a los hombres de la Edad del Bronce por considerarlos una raza viciosa (cfr. GRIMAL, Pierre: Diccionario de mitología griega y romana, Barcelona, Ediciones Paidos, 1993, p. 135; la descripción del diluvio y de las situaciones vividas por este héroe, llamado el "Noé griego", y su esposa Pirra pueden verse en OVIDIO NASÓN, P.: Metamorfosis. Edición de Antonio Ruiz de Elvira, Madrid, Consejo Superior de Investigaciones Científicas, 1988, vol. I, p. 17 y ss.). 
de todo el contexto. Explicárame un ejemplo de que usa el padre Kirquer, ${ }^{24}$ corrigiendo este abuso. Trazaba un compositor el canto para este versículo: Mors Festinat Luctuosa. Pues, ¿qué hizo? En las voces Mors y Luctuosa metió una solfa triste; pero, en la voz Festinat, que está enmedio, como significa celeridad y presteza, plantó unas carrerillas alegres que al rocín más pesado, si las oyera, le harían dar cabriolas.

37. Otro tanto, y aún peor, vi en una de las lamentaciones que cité arriba, la cual en la cláusula: Deposita est vehementer non habens consolatorem, señalaba Airoso. ¡Qué bien viene lo airoso para aquella lamentable caída de Jerusalén, o de todo el género humano oprimido de el peso de sus pecados, con la agravante circunstancia de faltar consuelo en la desdicha! Pero la culpa tuvo aquel adverbio vehementer, porque la expresión de vehemencia le pareció al compositor que pedía música viva; y, así, llegando allí, apretó el paso, y para el vehementer gastó en carrerillas unas cuarenta corcheas; siendo así que aun esta voz, mirada por sí sola, pedía muy otra música, porque allí significa lo mismo que Gravisime, expresando enérgicamente aquella pesadez, o pesadumbre con que la ciudad de Jerusalén, agobiada de la brumante carga de sus pecados, dio en tierra con templo, casas y muros.

38. En este defecto cayó, más que todos, el célebre Durón, ${ }^{25}$ en tanto grado, que a veces dentro de una misma copla variaba seis $u$ ocho veces los afectos de el canto, según se iban variando los que significaban por sí solas las dicciones de el verso. Y aunque era menester para esto grande habilidad, como de hecho la tenía, era muy mal aplicada" ${ }^{26}$

\footnotetext{
${ }^{24}$ Se refiere Feijoo al jesuita, historiador, teólogo y teórico musical alemán Athanasius Kircher (1601-1680), autor del tratado Musurgia universalis, sive Ars magna consoni et dissoni (Roma, 1650), de amplia difusión e influencia entre las obras teóricas del período barroco. Gran parte de la exposición contrapuntística del Musurgia universalis proviene de Zarlino. En muchos aspectos, el tratado sintetiza los procedimientos compositivos de los siglos XVI y XVII en Italia y Alemania. Sin embargo, un rasgo específicamente germánico es la descripción de la naturaleza afectiva de la música, en la cual Kircher utiliza el término musica pathetica en relación con los elementos constructivos y formales de la retórica (cfr. BUELOW, George J.: "Kircher, Athanasius". En: The New Grove Dictionary of Music and Musicians. Edición de Stanley Sadie, London, Macmillan Publishers Limited, 1980, vol. 10, pp. 73-74).

${ }^{25}$ Feijoo acusó a (1660-1716) Durón Sebastián de introducir el estilo italiano en la música religiosa española. Citamos un fragmento del párrafo 31 del capítulo VIII de su discurso: "Ésta es la música de estos tiempos con que nos han regalado los italianos por mano de su aficionado el maestro Durón, que fue el que introdujo en la música de España las modas estranjeras. Es verdad que después acá se han apurado tanto éstas que si Durón resucitara ya no las conociera, pero siempre se le podrá echar a él la culpa de todas estas novedades, por haber sido el primero que les abrió la puerta".
}

${ }^{26}$ FEYJOO: Op. cit., pp. 304-307. 
Pág. 12, lín. 19 y ss.: Corominas se muestra aquí contrario a la apología que hace Feijoo del canto llano en el capítulo III de su discurso, el cual transcribimos a continuación:

"7. Oh, cuánto mejor estuviera la Iglesia con aquel canto llano, que fue el único que se conoció en muchos siglos, y en que fueron los máximos maestros de el orbe los monjes de San Benito (incluyendo en primer lugar a San Gregorio el Grande y al insigne Guido Aretino); hasta que Juan de Murs, ${ }^{27}$ dotor de la Sorbona, inventó las notas que señạlan la varia duración de los puntos. En verdad que no faltaban en la sencillez de aquel canto melodías muy poderosas para conmover y suspender dulcemente los oyentes. Las composiciones de Guido Aretino se hallaron tan patéticas que, llamado de su monasterio de Arezzo por el papa Benedicto VIII, no le dejó apartar de su presencia hasta que le enseñó a cantar un versículo de su Antifonario, como se puede ver en el cardenal Baronio al año de 1022. Éste fue el que inventó el sistema músico moderno, o progresión artificiosa, de que aún hoy se usa, y se llama la Escala de Guido Aretino, y juntamente la pluralidad harmoniosa de las voces y variedad de consonancias, la cual si, como es más verisímil, fue conocida de los antiguos, ya estaba perdida de el todo su noticia.

8. Una ventaja grande tiene el canto llano ejecutado con la debida pausa para el uso de la Iglesia, y es que, siendo, por su gravedad, incapaz de mover los afectos que se sugieren en el teatro, es aptísimo para inducir los que son proprios de el templo. ¿Quién, en la majestad sonora de el himno Vexilla Regis, en la gravedad festiva de el Pange lingua, en la ternura luctuosa de el Invitatorio de Difuntos, no se siente conmovido, ya a veneración, ya a devoción, ya a lástima? Todos los días se oyen estos cantos y siempre agradan; al paso que las composiciones modernas, en repitiéndose cuatro, o seis veces, fastidian.

9. No por eso estoy reñido con el canto figurado, o como dicen comúnmente, de órgano. Antes bien conozco que hace grandes ventajas al llano, ya porque guarda sus acentos a la letra, lo que en el llano es imposible, ya porque la diferente duración de los puntos hace en el oído aquel agradable efecto que en la vista causa la proporcionada desigualdad de los colores. Sólo el abuso que se ha introducido en el canto de órgano me hace desear el canto llano; al modo que el paladar busca ansioso el manjar menos noble, pero sano, huyendo de el más delicado, si está corrupto" ${ }^{28}$

\footnotetext{
${ }^{27}$ Se trata del matemático, astrónomo y teórico musical francés Jehan des Murs, latinizado Johannes de Muris (ca. 1300-ca. 1350), autor del influyente tratado Ars nove musice. Corominas lo cita también en la pág. 16, lín. 6 del Aposento.

${ }^{28}$ FEYJOO: Op. cit., pp. 291-292.
} 
Pág. 14, lín. 15: desatiende aquí Corominas todo lo que pueda escribir Feijoo en el capítulo IV, que conviene citar íntegramente:

"10. ¿Qué oídos bien condicionados podrán sufrir en canciones sagradas aquellos quiebros amatorios, aquellas inflexiones lascivas que, contra las reglas de la decencia, y aun que de la música, enseñó el demonio a los comediantes y éstos a los demás cantores? Hablo de aquellos leves desvíos que con estudio hace la voz de el punto señalado, de aquellas caídas desmayadas de un punto a otro, pasando no sólo por el semitono, mas también por todas las comas intermedias; tránsitos que ni caben en el arte ni los admite la naturaleza.

11. La experiencia muestra que las mudanzas que hace la voz en el canto por intervalos menudos, así como tienen en sí no sé qué de blandura afeminada, no sé qué de lubricidad viciosa, producen también un afecto semejante en los ánimos de los oyentes, imprimiendo en su fantasía ciertas imágenes confusas que no representan cosa buena. En atención a estos muchos de los antiguos, y especialmente los lacedemonios repudiaron como nocivo a la juventud el género de música llamado chromático, el cual introduciendo bemoles y substenidos divide la octava en intervalos más pequeños que los naturales $[\ldots]^{29}$. Supónese que, con más razón, reprobaron también el género llamado enharmónico, el cual añadiendo más bemoles y substenidos, y juntándose con los otros dos géneros, diatónico y cromático que necesariamente le preceden, deja dividida la octava en mayor número de intervalos, haciéndolos más pequeños. Por consiguiente, en esta mixtura, desviándose la voz a veces de el punto natural por espacios aun más cortos, conviene, a saber, los semitonos menores, resulta una música más molificante que la de el cromático.

12. ¿No es harto de lamentar que los cristianos no usemos de la precaución que tuvieron los antiguos para que la música no pervierta en la juventud las costumbres? Tan lejos estamos de eso que ya no se admite por buena aquella música que, así en las voces humanas como en los violines, no introduce los puntos que llaman estraños a cada paso, pasando en todas partes de el diapasón de el punto natural al accidental; y ésta es la moda. No hay duda que estos tránsitos manejados con sobriedad, arte y genio producen un efecto admirable, porque pintan las afecciones de la letra con mucha mayor viveza y alma que las progresiones de el diatónico puro, y resulta una música mucho más expresiva y delicada. Pero son poquísimos los compositores cabales en esta parte, y esos poquísimos echan

${ }^{29}$ Feijoo incluye aquí la siguiente cita de Cicerón: "Chromaticum creditur repudiantum pridem fuisse genus, quod adolescentum remollescerent eo genere animi; Lacædemones improbasse feruntur (lib. I. Tuscul. quæst.)". 
a perder a infinitos que, queriendo imitarlos, y no acertando con ello, forman, con los estraños que introducen, una música ridícula, unas veces insípida, otras áspera; y cuando menos lo yerran, resulta aquella melodía de blanda y lasciva delicadeza, que no produce ningún buen efecto en la alma, porque no hay en ella expresión de algún efecto noble; sí, sólo, de una flexibilidad lánguida y viciosa. $\mathrm{Si}$, con todo, quisieren los compositores que pase esta música porque es de la moda, allá se lo hayan con ella en los teatros y en los salones, pero no nos la metan en las iglesias, porque para los templos no se hicieron las modas. Y si el Oficio Divino no admite mudanza de modas, ni en vestiduras ni en ritos, ¿por qué la ha de admitir en las composiciones músicas?

13. El caso es que esta mudanza de modas tiene en el fondo cierto veneno, el cual descubrió admirablemente Cicerón, cuando advirtió que en la Grecia, al paso mismo que declinaron las costumbres hacia la corruptela, degeneró la música en su antigua majestad hacia la afectada molicie: o porque la música afeminada corrompió la integridad de los ánimos; o porque, perdida y estragada, ésta, con los vicios, estragó también los gustos, inclinándolos a aquellas bastardas melodías que simbolizaban más con sus costumbres [...]. ${ }^{30}$ De suerte que el gusto de esta música afeminada, o es efecto o causa de alguna relajación en el ánimo. Ni por eso quiero decir que todos los que tienen este gusto adolecen de aquel defecto. Muchos son de severísimo genio y de una virtud incorruptible, a quien no tuerce la música viciada; pero gustan de ella, sólo porque oyen que es de la moda; y aun muchos sin gustar, dicen que gustan, sólo porque no los tengan por hombres de el siglo pasado, o, como dicen, de las calzas atacadas, y que no tienen la delicadeza de gusto de los modernos". ${ }^{31}$

Pág. 14, lín. 17: "quiebros". La acepción de "quiebros" como trinos o notas de adorno puede verse en Tomás de Santa María (ca. 1515-1570) ${ }^{32}$. Por otra parte, "quiebro", en Aut., es "la pausa breve y harmoniosa que se hace con la voz en un gorjeo, cantando, y como quebrándola".

Pág. 16, lín. 6: Cita aquí Corominas a "Juan de Murs". Véase la nota 27.

${ }^{30}$ Feijoo incluye aquí la siguiente cita de Cicerón: "Civitatumque hoc multarum in Græcia interfuit, antiquum vocum servare modum: quarum mores lapsi, ad mollitiem pariter sunt immutati in cantibus; aut hac dulcedine, corruptelaque depravati, vt quidam putant: aun cum severitas morum ob alia vitia ocidisset, tum fuit in auribus, animisque mutatis etiam huic mutationi locus. (lib. de legibus)".

${ }^{31}$ FEYJOO: Op. cit., pp. 292-294.

32 SANCTA MARÍA, Thomás de: Libro llamado arte de tañer fantasía, Valladolid, Francisco Fernández de Córdoua, 1565, ff. 46v-52r. Hay edición facsímil a cargo de Denis Stevens, en Heppenheim, Gregg International Publishers Limited, 1972. 
Págs. 16-17, desde las dos últimas líns. de la pág. 16 hasta la primera línea de la pág. 17: "¿Y quién no se reiría mucho más de ver empeñado a Epicuro en decirle requiebros a un dolor de muelas?" Humorada de Corominas hacia la doctrina del filósofo griego Epicuro (341-270 a. J. C.). En efecto, el epicureísmo propugnaba que el bien primitivo y natural del hombre era el placer, previa supresión del dolor, y que la felicidad se alcanza mediante un uso racional de ese placer.

Pág. 19, última lín.: "Apeles". Referencia al célebre pintor y tratadista griego de principios del siglo III a. J. C.

Pág. 20, primera lín.: "Francisco Palomino". No hallamos datos de este "Apeles de nuestros tiempos" como le califica Corominas en la última lín. de la pág. 19. Es posible que el violinista se refiera a Antonio Palomino (1655-1726), ${ }^{33}$ pintor del rey, estudioso, hombre de extensa cultura y tratadista de arte, que publicó el libro El museo pictórico y escala óptica (1715-1724),,$^{34}$ obra didáctica muy completa sobre la técnica pictórica, cuyo tercer y último volumen, titulado El Parnaso español pintoresco laureado, ${ }^{35}$ está compuesto por más de doscientas biografías de artistas, entre las que, sin embargo, no aparece Francisco Palomino.

Pág. 21, lín. 11 y ss: Recuerda aquí Corominas a Feijoo que alabó la música moderna en el capítulo $\mathrm{V}$ de su discurso, cuyos párrafos conviene citar:

"14. Sin embargo, confieso que hoy salen a luz algunas composiciones excelentísimas, ora se atienda la suavidad de el gusto, ora la sutileza de el arte. Pero, a vueltas de éstas, que son bien raras, se producen innumerables que no pueden oírse. Esto depende, en parte, de que se meten a compositores los que no lo son, y, en parte, de que los compositores ordinarios se quieren tomar las licencias ${ }^{36}$ que son proprias de los maestros sublimes.

33 Véase AGUILAR PIÑAL: Op. cit., 1991, tomo VI, pp. 261b-263a.

${ }^{34}$ Véase la edición moderna en SÁNCHEZ CANTÓN, Francisco Javier: Fuentes literarias para la historia del arte español, Madrid, Junta para Ampliación de Estudios e Investigaciones Científicas, tomo III, 1934, pp. 143-291.

${ }^{35}$ Ibidem, 1936, tomo IV, pp. 1-416.

${ }^{36}$ De idéntica forma se pronunciaba Cerone, más de un siglo antes que Feijoo, sobre este tipo de liencias. El teórico bergamasco aleccionaba así al discípulo: "Mas, sobre todo, adviertas que no les enmiendes sus composiciones [a los maestros], si, a veces, hallares en ellas cosa que sea contra las reglas que te enseñaron, porque es permitido al maestro usar en sus composiciones de los pasos que deveda a sus dicípulos; y es que, si el maestro hace un paso que sea contra las reglas musicales, los que ven aquel tal paso, y conocen por fama la persona que lo hizo, le atribuirán a licencia que llaman poética (que es permitida a los que tienen ya ganado el nombre de buenos compositores, por haber publicado diversas obras en las cuales dieron a conocer que ya saben distinguir lo bueno de lo malo) y no a ignorancia. Mas, si un mancebo, que todavía está 
15. Hoy le sucede a la música lo que a la cirugía. Así como cualquiera sangrador de mediana habilidad, luego toma el nombre y ejercicio de cirujano, de el mismo modo cualquiera organista o violinista de razonable destreza se mete a compositor. Esto no les cuesta más que tomar de memoria aquellas reglas generales de consonancias y disonancias; después buscan el airecillo que primero ocurre, o el que más les agrada, de alguna sonata de violines, entre tantas como se hallan ya manuscritas, ya impresas; forman el canto de la letra por aquel tono y, siguiendo aquel rumbo, luego, mientras que la voz canta, la van cubriendo, por aquellas reglas generales, con un acompañamiento seco, sin imitación, ni primor alguno; y en las pausas de la voz entra la bulla de los violines por el espacio de diez o doce compases, o muchos más, en la forma misma que la hallaron en la sonata de donde hicieron el hurto. Y aun eso no es lo peor, sino que algunas veces hacen unos borrones terribles; o ya porque para dar a entender que alcanzan más que la composición trivial, introducen falsas ${ }^{37}$ sin prevenirlas, ni abonarlas; o ya porque viendo que algunos compositores ilustres, pasando por encima de las reglas comunes, se toman algunas licencias, como dar dos quintas, o dos octavas seguidas, o lograr otro primor harmonioso, que sin esa licencia no se pudiera conseguir (y aún eso es con algunas circunstancias y limitaciones), toman osadía para hacer lo mismo sin tiempo ni propósito con que dan unos batacazos intolerables en el oído.

16. Los compositores ordinarios, queriendo seguir los pasos de los primorosos, aunque no caen en yerros tan groseros, vienen a formar una música, unas veces insípida y otras áspera. Esto consiste en la introducción de accidentales y mudanza de tonos dentro de la misma composición, de que los maestros grandes usan con tanta oportunidad, que no sólo dan a la música mayor dulzura, pero mucho más valiente expresión de los afectos que señala la letra. Algunos estranjeros hubo felices en esto, pero ninguno más que nuestro don Antonio de Literes [1673-1747], compositor de primer orden, y acaso el único que ha sabido juntar toda la majestad y dulzura de la música antigua con el bullicio de la moderna; pero, en el mane-

en reputación de dicípulo, uno que no tiene compuesto ni publicado obras, y uno que por fama no es conocido, hiciere el mesmo paso licencioso, los profesores que entienden le atribuirán a ignorancia, y no a licencia poética. [...] Y así digo que todo lo que los buenos músicos hacen fuera de arte, es licencia a todos los doctos concedida, y entredicha a los aprendices, y sin que nadie quede agravado" (CERONE: Op. cit., p. 96).

37 "Falsa", en Aut., sexta acepción de "falso", se describe así: "En la música, es la consonancia que, por haberse dividido en tonos y semitonos, sale redundante por tener un semitono más de los que toca a su proporción, u diminuta por faltarle a su proporción un semitono". Aut. hace constar que esta definición proviene del tratado Música universal (Madrid, 1717), escrito por el matemático y teórico musical Pedro de Ulloa (1663-1721). 
jo de los puntos accidentales es singularísimo, pues casi siempre que los introduce, dan una energía a la música correspondiente al significado de la letra que arrebata. Esto pide ciencia y numen, pero mucho más numen que ciencia: y así se hallan en España maestros de gran conocimiento y comprehensión que no logran tanto acierto en esta materia, de modo que en sus composiciones se admira la sutileza de el arte sin conseguirse la aprobación de el oído.

17. Los que están desasistidos de genio y, por otra parte, gozan no más que una mediana inteligencia de la música, meten falsas, introducen accidentales y mudan tonos sólo porque la moda lo pide, y porque se entienda que saben manejar estos sainetes, pero, por la mayor parte, no logran sainete alguno y aunque no faltan a las reglas comunes, las composiciones salen desabridas, de suerte que ejecutadas en el templo conturban los corazones de los oyentes, en vez de producir en ellos aquella dulce calma que se requiere para la devoción y recogimiento interior.

18. Entre los primeros y los segundos media otro género de compositores que, aunque más que medianamente hábiles, son los peores para las composiciones sagradas. Éstos son aquellos que juegan de todas las delicadezas de que es capaz la música, pero dispuestas de modo que forman una melodía bufonesca. Todas las irregularidades de que usan ya en falsas, ya en accidentales, están introducidas con gracia, pero una gracia muy diferente de aquella que San Pablo pedía en el canto eclesiástico, escribiendo a los Colosenses: In gratia cantantes in cordibus vestris Deo. Porque es una gracia de chufleta, una harmonía de chulada; y así, los mismos músicos llaman jugueticos y monadas a los pasajes que encuentran más gustosos en este género. ¿Esto es bueno para el templo? Pase norabuena en el patio de las comedias, en el salón de los saraos, pero, ¿en la Casa de Dios chuladas, monadas y juguetes? ¿No es éste un abuso impío? ¿Querer que se tenga por culto de la deidad, no es un error abominable? ¿Qué efecto hará esta música en los que asisten a los Oficios? Aun a los mismos instrumentistas al tiempo de la ejecución los provoca a gestos indecorosos, y a unas risillas de mojiganga. En los demás oyentes no puede influir sino disposiciones para la chocarrería y la chulada.

19. No es esto querer desterrar la alegría de la música; sí, sólo, la alegría pueril y bufona. Puede la música ser gustosísima y juntamente noble, majestuosa, grave que excite a los oyentes a afectos de respecto y devoción. $\mathrm{O}$, por mejor decir, la música más alegre y deliciosa de todas es aquella que induce una tranquilidad dulce en la alma, recogiéndola en sí misma y elevándola, digámoslo así, con un género de rapto estático sobre su proprio cuerpo para que pueda tomar vuelo el pensamiento hacia las cosas divinas. Ésta es la música alegre que aprobaba San Augustín, como útil en el templo, tratando de nimiamente severo a San Athanasio en reprobarla, 
porque su proprio efecto es levantar los corazones abatidos de las inclinaciones terrenas a los afectos nobles $[\ldots] .^{38}$

20. Es verdad que son pocos los maestros capaces de formar esta noble melodía, pero, los que no pueden tanto, conténtense con algo menos, procurando siquiera que sus composiciones inclinen a aquellos actos interiores que de justicia se deben a los Oficios Divinos; o, por lo menos, que no exciten a los actos contrarios. En todo caso, aunque sea arriesgándose al desagrado de el concurso, evítense esos sainetes cosquillosos que tienen cierto oculto parentesco con los afectos vedados, pues de los dos males en que puede caer la música eclesiástica, menos inconveniente es que sea escándalo de las orejas, que el que sea incentivo de los vicios" ${ }^{\prime \prime}{ }^{9}$

Pág. 24, líns. 8 y 9: Menciona aquí Corominas una figuras denominadas "tricorcheas" y "cuatricorcheas". El padre Feijoo se había referido a ellas en el capítulo III, párrafo 26 de su discurso, en estos términos:

"Se inventaron no ha mucho las tricorcheas que parten por mitad las semicorcheas. No paró aquí la extravagancia de los compositores y inventaron las cuatricorcheas, de tan arrebatada duración que, apenas, la fantasía se hace capaz de cómo en un compás pueden caber sesenta y cuatro puntos. No sé que se hayan visto hasta este siglo figuradas las cuatricorcheas en alguna composición, salvo en la descripción del canto de el ruiseñor que, a la mitad de el siglo pasado, hizo estampar el padre Kirquer en el libro primero de su Musurgia Universal; y aún creo que tiene aquella solfa algo de lo hiperbólico, porque se me hace difícil que aquella ave, bien que dotada de órgano tan ágil, pueda alentar sesenta y cuatro puntos distintos mientras se alza y baja la mano en un compás regular." ${ }^{40}$

Por nuestra parte, no hemos hallado descritas estas figuras con esos nombres en los tratadistas musicales más importantes de la época. En Andrés Lorente (1624-1703) se nombran dos figuras más de las ocho habituales, es decir, de la máxima, longa, breve, semibreve, mínima, semínima, corchea y semicorchea. Dice Lorente: "Otras dos figuras añadieron los modernos a las referidas; y las pusieron por nombre minaria y fusea. Hiziéronlo porque volase más el canto; no están en uso, y así no trato de ellas". ${ }^{41}$ Fray Pablo Nassarre (ca. 1664-1730), por su parte, señala que

${ }^{38}$ Feijoo incluye aquí la siguiente cita de las Confesiones de San Agustín: “Ut per hæe oblectamenta aurium infirmior animus in affectum pietatis assurgat. (lib. 10 Confess. Cap. 32)".

${ }^{39}$ FEYJOO: Op. cit., pp. 295-298.

${ }^{40}$ Ibidem, pp. 300-301.

${ }^{41}$ LORENTE, Andrés: El porqué de la música, Alcalá de Henares, 1672, p. 147. 
"otras dos figuras, a más de las ocho que he dicho arriba, han inventado los modernos, a las que llaman fusas y semifusas, y otros garapateas y semigarapateas. No están muy puestas en práctica y por eso no las puse en el número de las antecedentes. [...] Tengo por ociosa la invención de estas figuras últimas, porque si ha sido el fin de sus inventores la mayor velocidad, no hay necesidad de ellas, porque la semicorchea puede correr con tanta velocidad como la semifusa, pues consiste en la aceleración del compás el ser más o menos veloces las figuras, y por esta misma razón juzgo que no están sobradamente introducidas la fusa y semifusa, pues si hubieran hallado ser muy útiles, en más de cien años que ha que están inventadas, se usarán más. Pues la semifusa especialmente en España no se ve practicada en ningua obra música para instrumentos, que es donde más se practica la velocidad de figuras" ${ }^{42}$

Pág. 24, lín. 15: Cita aquí Corominas a "Anastasio Kirker". Véase nuestra referencia en la nota 24.

Pág. 26, lín. 16: "Orbaneja el de Úbeda". No hemos hallado referencias sobre este nombre.

Pág. 28, líns. 7-9: "En ésta fue insigne Durón, y jamás pudo llegar a poseer aquélla, porque estaba ya viejo Pedro". Feijoo criticó al maestro Sebastián Durón (1660-1716) en el párrafo 38 del capítulo IX de su discurso (véase la cita correspondiente en la pág. 11, líns. 18-19, del Aposento). Corominas le defiende, pero no entendemos por qué le llama "Pedro".

Pág. 28, lín. 14: Cita aquí Corominas los capítulos IX y X del discurso feijoano. Con anterioridad, en la pág. 11, líns. 18-19, ya había citado el "párrafo [=capítulo] nono" que nosostros transcribimos allí. Llega ahora el turno para el capítulo X:

"39. Algunos (porque no dejemos esto por decir) juzgan que el componer la música apropriada a los asumptos consiste mucho en la elección de los tonos, y, así, señalan uno para asumptos graves, otro para los alegres, otro para los luctuosos, \&c. Pero, yo creo que esto hace poco o nada para el caso, pues no hay tono alguno en el cual no se hayan hecho muy expresivas y patéticas composiciones para todo género de afectos ${ }^{43}$. El di-

\footnotetext{
42 NASSARRE, Pablo: Escuela música según la práctica moderna, Zaragoza, Herederos de Diego de Larvmbe, 1724, p. 217; hay edición facsímil a cargo de Lothar Siemens Hernández, en Zaragoza, Institución Fernando el Católico, 1980, 2 vols.

${ }^{43}$ Otra opinión, que relativiza también la teoría del ethos musical, es la que daba Cerone: "Para esto será de mucha consideración si el composidor [sic] terná [=tendrá] cuenta de tomar un tono apropriado al sentido de las palabras, como sería, a decir, si las palabras serán de tristeza, tomar un tono triste, y si fueren de alegría, tomar un tono alegre. Aunque es más que verdad que un
} 
ferente lugar que ocupan los dos semitonos en el diapasón (que es en lo que consiste la distinción de los tonos) es insuficiente para inducir esa diversidad, ya porque, donde quiera que se introduzca un accidental (y se introducen a cada paso), altera ese orden; ya porque varias partes o las más de la composición, variando los términos, cogen los semitonos en otra positura que la que tienen respecto de el diapasón. Pongo, por ejemplo, aunque el primer tono, que empieza por Delasolre, vaya por este orden: primero un tono, luego un semitono, después tres tonos a quienes sigue otro semitono y en fin un tono, los diferentes rasgos de la composición, tomado cada uno de por sí, no siguen ese orden, porque uno empieza en el primer semitono, otro en el tono que está después de él, y así de todas las demás partes de el diapasón, y acaban donde más bien le parece al compositor, con que en cada rasgo de la composición se varía la positura de los semitonos, tanto como en los diferentes diapasones que constituyen la diversidad de los tonos.

40. Esto se confirma con que los mayores músicos están muy discordes en la designación de los tonos respectivamente a diversos afectos. El que uno tiene por alegre, otro tiene por triste, el que uno por devoto, otro por juguetero. Los dos grandes jesuitas, el padre Kirquer y el padre Dechales ${ }^{44}$ están en esto tan opuestos que un mismo tono le caracteriza el padre Kirquer de este modo: Harmoniosus, magnificus, \& regia maiestate plenus. Y el padre Dechales dice: Ad tripudia $\mathcal{E}$ choreas est comparatus diciturque propterea lascibus. Y poco menos discrepan en señalar los caracteres de otros tonos bien que no de todos.

41. Lo dicho se entiende de la diversidad esencial de los tonos, que consiste en la diversa positura de los semitonos en el diapasón, pero no de la diversidad accidental que consiste en ser más altos o más bajos. Ésta algo puede conducir, porque la misma música puesta en voces más bajas es más religiosa y grave, y trasladada a las altas, perdiendo un poco de la ma-

buen composidor ordenará que todos los tonos sean melancólicos, o alegres, como él quisiere; y esto por acompañar las consonancias cuando de una y cuando de otra manera, usando, a veces, muchas terceras y sextas menores, con muchas disonancias y ligaduras, $y$, a veces, usando muchas sextas y terceras mayores, y muchas decenas. $Y$ también (como dicho es) porque procederá en las partes de su composición con movimientos espaciosos y largos, o ligeros y breves" (CERONE: Op. cit., p. 666, los bubrayados son del autor).

${ }^{44}$ Se refiere Feijoo al filósofo y matemático francés René Descartes (1596-1650), autor del célebre Compendium musicæ (Utrecht, 1650), que es, a la vez, un tratado musical y un estudio sobre metodología, en el que el propio Descartes se considera a sí mismo como el punto de enlace entre los humanistas musicales del siglo XVI y los científicos del XVII. Descartes divide la música en tres componentes básicos, cada uno de los cuales puede estudiarse aisladamente: el aspecto matemático y físico del sonido, la naturaleza de la percepción sensorial y el efecto que tal percepción produce en el individuo (cfr. COHEN, Albert: "Descartes, René". En: The New Grove Dictionary..., vol. 5, p. 387). 
jestad, adquiere algo de viveza alegre, por cuya razón soy de sentir que las composiciones para las iglesias no deben ser muy subidas, pues, sobre que las voces en el canto van comúnmente violentas y por tanto suenan ásperas, carecen de aquel fácil juego que es menester para dar las afecciones que pide la música, y aun muchas veces claudican en la entonación; digo que, a más de estos inconvenientes, no mueven tanto los afectos de respeto, devoción y piedad como si se formaran en tono más bajo". ${ }^{45}$

Pág. 28, lín. 16: Cita aquí Corominas a "Dechales", o sea, Descartes. Véase nuestra referencia en la nota 44.

Pág. 29, lín. 10: Cita aquí Corominas al "padre Marino Merseno" que no es otro que el matemático, filósofo y teórico musical francés Marin Mersenne (1588-1648), autor, entre otros, de los libros teóricos Traité de l'harmonie universelle (Paris, 1627) y Harmonie universelle (Paris, 1636). Mersenne y Descartes cultivaron una estrecha amistad y se influenciaron mutuamente. Entre las múltiples facetas científicas y teóricas de Mersenne destacan sus aportaciones a la organología que parten, en primera instancia, de las obras de Michael Praetorius ${ }^{46}$.

Pág. 29, líns. 14-15: "Círculo músico". Se refiere Corominas al círculo armónico o tonal, llamado también círculo o ciclo de quintas, en uso ya a principios del siglo XVIII, y que sistematizó el compositor y teórico alemán Johann David Heinichen (1683-1729), en su tratado Der GeneralBass in der Composition (Dresden, 1728).

Pág. 29, líns. 15-19: “Aun en el célebre órgano que fabricó el insigne Pomar y presentó al Señor Rey Phelipe cuarto, y cuya división aritmética halló D. Félix Falcó, no obstante tener cinco órdenes de teclas". Según María Sanhuesa, Félix Falcó de Belaochaga, matemático, teórico musical y poeta activo en Valencia entre los siglos XVII y XVIII, "trabajó en la división de la octava en 31 partes, calculándola numéricamente [y] subsanó los defectos del instrumento de Pomar aplicando esta afinación a un clavicordio de cinco teclados en el que hacía su demostración" ${ }^{47}$

Pág. 32, lín. 10: "no me ponga en el número de los zoilos". "Zoilo", en Aut., es el "nombre que se aplica hoy al crítico presumido y maligno censurador o murmurador de las obras ajenas, tomado del que tuvo un

\footnotetext{
${ }^{45}$ FEYJOO: Op. cit., pp. 307-308.

${ }^{46}$ Cfr. COHEN, Albert: "Mersenne, Marin". En: The New Grove Dictionary..., vol. 12, pp. 188-190.

${ }^{47}$ Véase SANHUESA FONSECA, María: "Falcó de Belaochaga, Félix". En: Diccionario de la Música Española e Hispanoamericana..., vol. 5, pp. 885-886.
} 
rethórico crítico antiguo ${ }^{48}$ que, por dejar nombre de sí, censuró impertinentemente las obras de Homero, Platón e Isócrates".

Pág. 32, líns. 17-19: Ofrece Corominas a Feijoo, no sabemos si en tono zumbón, "un tratadito largo de las ventajas de la música moderna a la antigua, y del violín a todos los demás instrumentos". Si este "tratadito" llegó a escribirse y publicarse no ha llegado, de momento, hasta nosotros. ${ }^{49}$

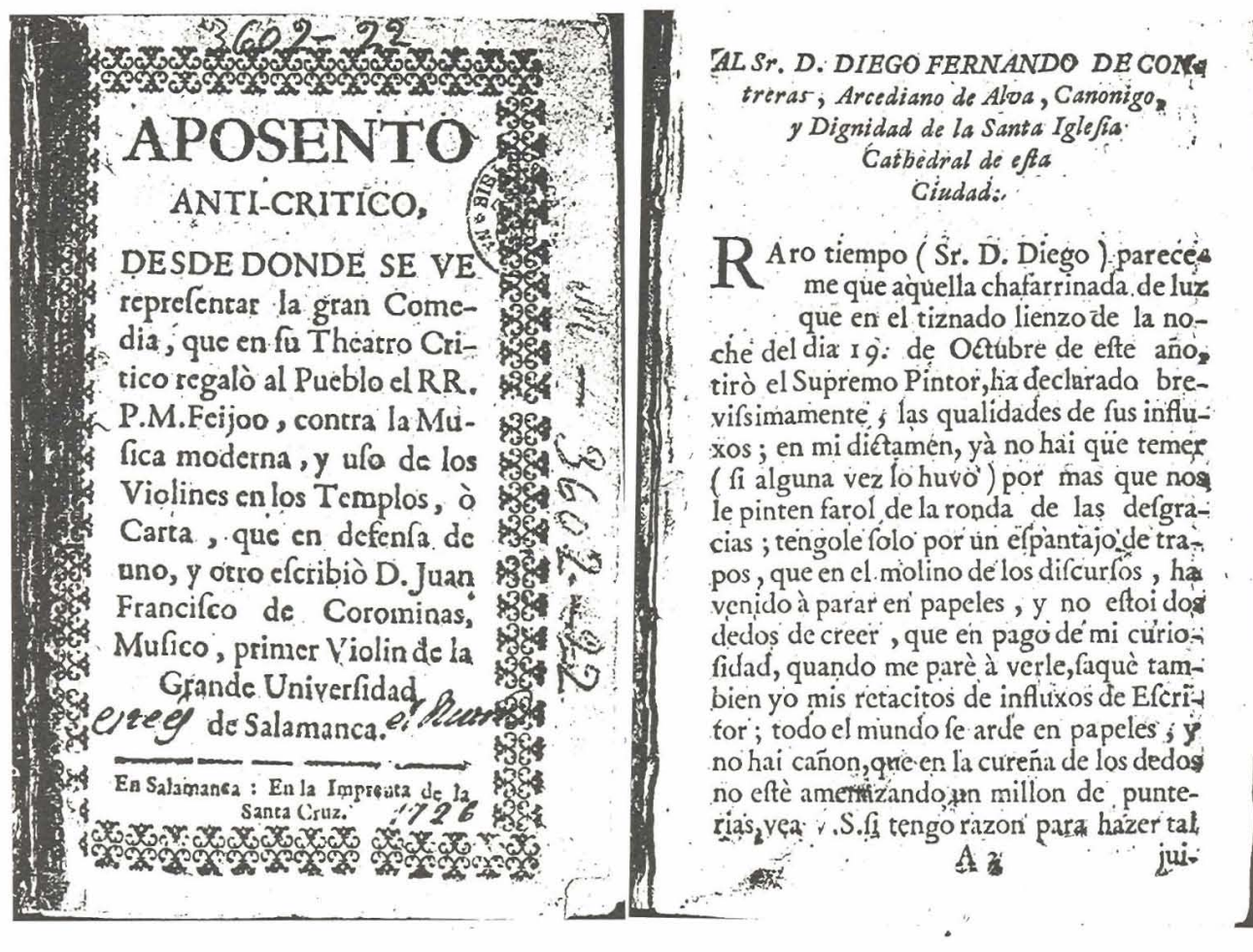

${ }^{48}$ Referencia al sofista griego Zoilo del siglo IV a. J. C., adversario de Isócrates y apodado el látigo de Homero por la severidad de sus críticas hacia los poemas homéricos.

${ }^{49}$ Cfr. MARTín MORENO: El Padre Feijoo y las ideologías musicales..., p. 227. 
juizio pero ño es éfo. Ilegò à mis ma:" nos, por una rara cafualidad, el Theatro Critico, que efcribiò el Rmo.P.Fr. Benito Feijoo (fi no temiera, que'por mia defpreciaffen la opinion, affeguràra à V.S. que le tengo por uno de los hombres grandes de nueftros tiempos ) y en uno de fus diffurfos, le notè intetefado eficazifsimaimente à favor de la antigua Mufica, y. opuefto enteramente al ufo de los Violines en los Ternplot. No me efpanto; que Muficas, y Violines he oido yo en ellos; que merecen mayor carga cerrada, que la que fú Rma. les dà ; pero como eftos ingenios grandes, eftos entendimientos de primera claffe, defpues de la eficazia que rienten para perfuadir, fuelen hazer regla 'géneral de fu gufto, paréciòme muy contra mi lo primero, y en cafo de fer lo fe. gupdo, hizele prefentes làs ražones en contrario en effa Carta. No pudo fer tais à puerta cerrada, que lo dexaffen de faber algưtos amigos; yà falga lo que faliere me la han hecho eftampar, y en efte tafo, à quien havia de recursitit para que

la

CENSURA DE D.FREYTOSEPH DEOV̈AN do y Solis, Colegial en el Imperial de Alcanta. ray Catbedrattio de Regencia de Arres en efta Univerfidad.

$\mathrm{CL}^{\mathrm{L}}$ papel que $\mathrm{Vmd}$ me remite, cuyo titulo es rpofento Anti-Gritico, ofc efcrito porDa Juan Corominas, he leido con la mayor infpeccion,y no hallo que contenga cofa contra 1a Santa Fé, y buenas coltumbres, con que fin efcrupulo el mas leve, puede Vmd conceder la licencia que fe pide. Ársi lo fiento. En efte Colegio Imperial del Orden de Alcantara del Emperador Carlos Quinto mi Scrior, Salamança, y Dlziembre Ir. de 1726.

D. Frey fofeph Antonio de Ovando y Salis.

LICENCIA DEL ORDINARIO.

TOs D.Francifco Antonio dc Elpinolia y Trevifo, Colegial Huefped del Mayor del.ıArçobifpo, Proviffor, Y Vicario General defte Obifpado, \&c. Por la prefente damos licencia à D. Juan Francitico Coromi nas para que pueda imprmir una Carta etcrita por el fjöodicho, por quanto de nuetitra orden eltà vifta, y na contrene cofa contra nueftra Santa Fe. Dada en Salamanca aे s o.de Diziembre de 1726 .2ños. Lir.Ejpinefs.

Por el Oficio que fue de Jann Ramos Por mandado del Sr. Provifior. Josept B/gisco.
Ia protexieffe ? V. S. mifmo fabe, que apenas hai otro de quien con mas derecho pueda ampatarfe, ni yo, ni la Mufica moderna. Su noble aficion à efte bellodivertimiento, fu efplendidez para con los de mi profefsion, y fu delicado gúfto eri todo lo tocable, ò cantable , neceffariamente ponen à V.S. del vando del gufto moderno, y à mi en la obligacion de con. fagrarle efte pequeno trabajo, acompañado de la mas prompta voluntad de fervir. ì. V.S. en quanto guftare mandarme.

Guarde Dios à V. S. muchos años. Saz amanca, y Dizicmbre 14. de 1726.

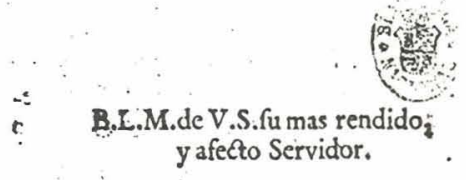

74toun Frencifco: $\quad 7.35$.
$A=$

Fol. $\mathrm{f:}^{\mathrm{a}}$

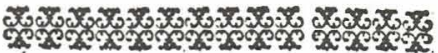

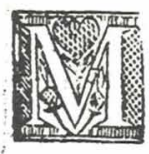

Ui Seńor mio, ruegòle à V. R. que por vida fuya no safgue efta Carta antes de oirla, llevado de la aprehenfion, de que atenderà quexas, y mas de Muficos ofendidos no puede acarrearle mas gufto, que una terrible zaravanda de dicterios con fus retazicos de folfa mendicante: no por cierto, fofieguefe V. R. y en ella mirma reconocerà , que tambien los Muficos fabemos llevar el contrapunto al refpeto; y gaftar Cromaticos cortcfes con aquellas perfonas, que aunque ignoradas de la vifta, faben hazerfe prefentes, $y$ venerables à la eftimacion, à fuerça de meritos, ý: autoridad. Nada menos intento que ofenderle, y nada quiero mas que reprefentarle al vivo la eftupenda commocion que entre algunos de ka piofésion ha c'ufado la rara, y peregrina feniencia, que V. $K$. contrz el coinun aplaufo de las gentes, 
\$.

g. puiverfalaprobación de Tíaras , ÿ Coz romas ha querido feguir, condenando à fitencio à-los Violines delante del Tribunal de Dios, y atandole à los Seńores Maeftros de efta facultad las manos, parz queno hagä fonar en las Iglcfias fino conceptos gordos en gaznates crafos, acompañados de unos golpecitos à compàs, como campanadas de mortuorio.

- Una tarde de iaspaftadas, que canfado de la deleitable tarea de la compoficion, me obligąron las cofquillas del'guftò̀ bufcar en êl quarto de otros amigos, y compañeros algun defahogo' de menos rrabajo à la cabeza, y à los dedos; fue quando empezò mi defafofiego. Aun no havia cumplido con aquellas cortefes ceremonias, que introduxo la politica, y traso racional, y yà havian defcargado fobre mi en afable zumba un abifmo de fentencias criticas, un enfarte de vituperios contra el Violin, y una cadena de proferipsiones de la pobre Murica moderna, que por cierto les preguatè, fi ovian saiucuia doalguna Paulina en la Nunciatura del mal

4

guna refolucion de alguna junta de infige nes Theologos, formada à efte fin, y eftaba tamañito ; mas fin detencion me pufieron un libro en la mano, que dezia:' Theatro. Critico Univerfal : Gracias à Dios, prorrumpi, que fali del fufto: En manos de Criticos ha dado nueftra Mufica? Yo sè que ella faldrà bien folfeada: tambien hai dientes para los Violines? Pues buenas les quedarán las coftillas, porque yà ni los hueffos tienen folidez para refiftir los dientes de la moda. Efcrito (dezia mas abaxo) por el Rmo. Padre Maefiro Fr, Benito Eeijoo. Valgame Dios, que un hombre como efte haya caido en tentacion $\tan$ perniciofa! Un hombre, que me han dicho que fabe, y efcribe de todas las cofas, y otras muchas mas, haya fido $\tan$ infeliz, que con un trampantojo ridiculo fe dexaffe perfuadir malamante 'à meterfe à profeffor de la Critica!No lo crcyera.Pero ccmo en eftas cofas caeremos, fila razon, y meollo fubftintivo con que nos criraon nitieftros Padres, nos dexan de fu mano. I cì , en fin, el parrafito de Violines ; $y$

$$
\text { bien, }
$$

mal gufto y fe enfayavan à 'recitarla por las reglas del Tribunal de Toledo? Como què ; refpondieron mas foffegados, à tè, que puede bufcar Vmd. modo de congraciarre con algun Autor de Farfa, ò alguno de los Señores, que por moda, ò aficion guftan de Violines, porque eftàn yà eftos inftrumentos anathematizados, excomulgados, y apartados del gremio de Nueftra Santa Madre la Iglefia Catholica, hanfe declarado por alborotadores de la publica feriedad, y feles pone filencio perpetuo por chilladores, y gritadores. Pobres Ninos de la Doetrina, dixe yo, fi por gritar excomulgan, en mi conciencia que $\mathrm{fe}$ quedaràn bacios los Seminarios, y Efcuclas de Nínos. Pero hablando feriamente; con que motivo me han dado Vmdes. efta carga cerrada, que con las buenas tarcies atravefadas en el gaznate, apenas Ime han dexado recobrar del miedo de quedarme para fiempre Violin de eftrado ? Lecra Vmd. dixo uno, y verà fu defyracia.

Difcurri cierto, que fueffe algun Breve de Nueftro Santifsimo Padre, o alguiaa

bien, me dixeron, que le parece à $\forall$ ma? Llevome tras si el primer movimiento de la Bilis, como à flaco pecador, y que ne ha. de parecer, dixe, una Dama de las ciuc configo lleva el bullicio cortefano, mucha feda, mucho afeite, y fea mucha licrmofura por de fuera,y unAntonMartin por de dentro: un rofario de lagrimas cngazado en plata: una callejuela fucia tapada con un paño de Flandes en dia de procefsion: y mas claro, una eternidad de defpropofitos cubiertos co: una hermofa capa de palabritas bien colocadas. Detuveme aqui; porque conozco que flaquea mucho cl partido de la razon, quando fe vale de los improperios, como tropas auxiliarcs. Rieron bien mi fofocacion los companeros, $y$ preguntados de fu parecer, llenos de la modeftia, que acoftumbran, y apreherden de las mifmas lofas, que piffan, convinieron en que tamaño error, y fentencia tal, que milita contra todo el buen gerfto, y contra tan venerables circuaratiins, como rienen canonizadia la contraria, no era bien fe dexaffe paffar ì hazer comun 
voz delvulgo, cuyo dictamen, governa: conmigo fu libro; defperdiciè algunos do acafo por la authoridad de fu Maeftro, quartos de hora en leer todo el Dilcurfo difcurriendo generalmente por las Gentes $x_{4}$. hafta el $\$$. I1. Y quando me creia emalteraffe el comercio del oido, è hizieffe peñado en refponder folo à los breves tenperder todas las nuevas fabricas, obligan- glones, que efte incluye, me hallè de redonos à veftir las orejas de fones con cal- pente en la precifsion de tomar la cofatan zas atacadas. Díeronme la comifion 'como defde los principios, como V. R. la toma. à parte mas interefada) de defengañar à Supongo, Padre mio, que en efto de laV. R. y volver por el inftrumento, por el tines tengo poquifsimos alcanzes; porque noble fudor de tan altos ingenios, como fon los mios como los rayos de la Luna, oy trabaxań por apurar efte abifmo de Mu- per participationsm. Hanmelos pegado las fica, por el buen gufto de tantos, como lofas, que piffo, y los poftes, que venero por deleitable entretenimiento, ò le efcu- en los patios de efta Athenas. Y fi alguno chah, ò le tanen; $y$ finalmente de hazer faliere, y no bueno, no fe efpante, que : patentela laftima, que debemos todos te- tambien la Señora Luna fe queda à buenas ner à nueftros Abuelos, que fe fueran 2 noches muchas vezes; pero en lo que à otro thundo con los oidos cf́calabiados de mi Facultad toca, hame de perdonar que puntos gordos, y las folías de una Harpa grite, porque tengo mis libritos, y mis de una horden.

años de eftudio en ellos, y para femejan.

Azezela fin repugnáncia; yà por los tes ocafiones procuro traher los limpios del motivos referidos, yà tambien por dar $a_{1}$ - polvo de la ociofidad.

gur defahogo al defabrimiento, que me causò vèr los infubfiftentes fundamétos, con qué $V . R$, pretende defterrar el u fo de los. Violines en los Terniplos, y llevandome, fermoncico fobre lo mal que hizieron los COR-

Convengo defde łuego en aquel antiquifsimo ufo de la Mufica para las Aras folo; y eftaba yo por hazer tmabien mi

Señoxes Griegos en obligarlà à acomodar Comedias criticas , ò Sagradas Mifiones; fus numeros à los theatros, y à los fefti- digame fi las condena folo por fer de eftos. nes. En efto apriete, que à todos nos im tiempos, ò por rifar fiempre con la moda; porta. Que le parece à V: R. que qual., no advierte que fiempre fue lo mifmo, que quiera de mi profefsion que ò por necefsi. el mundo nada nuevo dà , fi no à tornos dad, ù otros respetos, firve de entreteni- de fu rueda vuelve à reprefentar en fu theamiento en una, ù otra parte, fale dè alli tro aquello mifme, que yà fue; que ficm. hecho Cavallero de algun Orden Militar, pre ha havido corrupciones, y criticifmos. ò con algun mayorazgo de Titulo en Cafti- Acuerdome muchas vezes, oyendo à otros, Ila? Pues fepàfe; que defpues de mui bien! que tambien tienen el genio gruñilo.2, y 'quebrados los dedos, y mas que bieir en- amigode preteritos rancios del maduro jui"cendida la cabeza, logra el dia figuiente'! cio, con que fe zumba de ellos el critico un par de giantes de la piel que fe le def- fin tacha, aquel de los feffos en la mollera, cofiò à tocar, y las mas vezes, un viva y la cabeza fobre los hombros; el gran Vmd. mil anos, que es el tabardillo mas cruel para quien ha de comer de fur trabajo. Peróagnel gran falto defde fa venerable antiguedid, hafta nueftros deteftables ticnipos, aquella notable exclamacion, ò declamacion; porque tambien fe oyen eri las Iglefias aquellos, hairecillos, Gue fueron la noche antes patto à la atencion de un' farao ; declarefe que tiene mucha vivacidad, $y$ a!gun tanto emipczè à diudar", fi eñ fu Theatro reptefentaba V.R.

Iorenzo Gracian. Introduce aquel corrillo, de Gentes femejantes, quexandofe de 10 prefente, blasfemando de lo futuro, exclamando contra la general deprabacion de las coftumbres de fu figlo, y fúpirando (no era por el canto llano) por los felizes tiempos de fus Padres, y Abuelos: açue. Ilo fi que era honra, dezian, entonces it que los hoinbres eran verdaderanicnse fubftantivos; y poco mas diftante en otio sorrillo aquellos mifmos Padres, yAbueios 
diziendo muchif́simo mas mal de fa tienz- Aagio ? Es pórquue no "fon tan graves? $Y_{\text {: }}$ po, que los primeros del fayo, ajuftene cormo lo nan'de fer, fi la letra aunque exeffas medidas : Padre,jamàs fue otra cofa, shale devótifsimos conceptos es alegrc, nunca dexò de fer lo mifmo, afsi, que ò cul- hafe de ceńir à una Muficica dormida? Sí penosigualmente, y igulamente nos ab- Nueftra Santa Madre la Iglefia previene fuelva;yfi los tacha por nơferios, è impro- Snuéftro gozo con' los repiques de fus Cámprios pasa etDivino Culto, digame, proferí- panas en la alegrifsima noche de Navida d, be los nöbres de Aria recitado, \&c.o lo que than de veftirfe lós Villancicos de luto'? Es debaxo de ellos fe comprehende ? Si lo primero, effer de cenfurar terminos dexelopor fu vida, que en tiempo eftamos, y en manos anda el pandero. Que ri aun acordarfe han querido de que $V$. $R$. vive para dar le Plaza en fu Academia, porque para efto , y algo mas fon Maiftros, que no necefsitan de Criticos univerfales, defpues de que las de nombre fiempre he oido que fon queftiones para nin̄os; y fi to fegundo, entremos en quentas, para çus es alabar contanta porfia la grande arte de veftir la Mufica del color de las palabras, la exprefsion pathetica de afeetos, y In fuave fuerça con que obran confpirader los conceptos Poeticos, y Mufícos; fi al cabo al cabo haviamos de dar' en efte

propifsinto dé aquella noche introducit Paftores', Negros, yotros'generos ded perfónas cantando ${ }^{2}$ y fol conceptos ha de explicarlos el Counpófitor côn claufulas

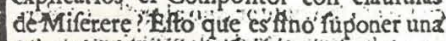

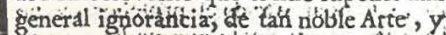
ficarla violetitatinlefte de fis fundámen-

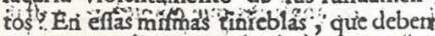
fer al gunos nébtulones, abortados por al gun Mufico de contravando, y cita V. R.

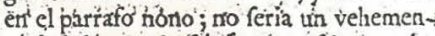
té defátino, valerfé de ex́prefsiones alegres'? Pues què fơn Arias, Minuetes, , yi Recitados? Quèe? Ura cierta compoficion cuyo nómbre diríge al cxecutor à t. per feeta modulación de lo que debaxo de sín çompet's de : fí V:R. imagina, que Aria,

y. Minuiete defde luego'fueva tararira, eni fias facil , y ajuftado, para no haver Cogánóde como menos praetico; helas oido, munidades de Muficos, fino de Religiotañölas, y tengòtas mui ferias, mui gra- fos, cuya fanta modeftia en nada debe ves : y mui melancolicas.' Juguete de las fer menos artificial, que en alabar à Dios, Calles es en efta Ciudad un Menuet, cu- fin que enquentrie yo mas razon para la ya trifte compoficion le grangeò el nom- irregular entonacion de lás Religionics rebre de Menuet de las Animas ; y ti hu-formadas. Hazele tambien venerable, no viera de citar obras en que todo efto fe folo fus inventores; fino tambien el largo halla unido, y refpiran mageftad, gufto, Kriempo que há fe ufa.en ella, y en la obfer y feriedad. fertia menefter algo mayor vancia de efto, ý fús fagradas ceremionias, y. Iomo que el del Theatro Critico. Si en treftiduras, derpués de nays altos fines, que las que $V, R$, ha vifto fuccede lo contrario, yo no comprehiendo, nos enféna fu efta. culpe al Corróritor, tio al gufto moder-. bilidad; $y$ uniformidad én tódos lós fino, efto es al Arte en el profetfor, y no Efcurelas; atra a los qué empiezan à gaftar el primer cótón de lass bayetas, fé debe bazer con las Cieticías todas:

De tales principios, que avia de fafir fíco fufpirar en todo el $8 \cdot 3 \cdot$ por el Can-: to llaso. P. Rmo. mite que es una llane22, incigna de un lion bre de buen guffo' tal propoficion, Eftilafc efté genero de Canto en la lglefia, no por fer lo mejor, no porlo mas periceto del Aste, fi por la glos ; en cuya alteracion ácafo havria mil inconvenientes' ; y es ridicula ilacion, la Iglefia no muda veftiduras, '́ni ceremo. nias : luego ni Mufica ; allà và effá: l lúego ni de Altares ; porque en ella no fefupo, que era oropeles; ni talco s hafta mui pocos ańos ha. Por la razon dicha nos fuetia fiempre bien'el Hymno Vexilla Regis, y el Invitatorio de Difuntos; miralos $I_{2}$ atenćion con un Religiofo'refpeto; que aunque 'fueran defagradables al oido; los hizlera-apacibilifsimos, tierie la picmas $\dot{B}_{2}$ dad 


\section{4

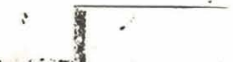

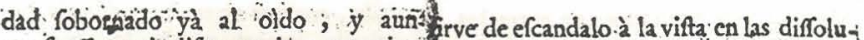 que fueffe mui diferente $\mathrm{la}$ entonacion, fiempri- fe moveriacon los afectos de tan o effo tiene la que con las mezclas de la fagradasletras, buena prueba es, que fi moda gafta en las Iglefiąs, la poca adyer - mudando de lugares oye qualquiera fusiencia de los Compofitores, y Exccutores: Campanas', que fupongo las fonaffen àj Javia en cierta Ciucdad un Abogacio, à fiefta, file advierten fu engaño, y le ex-guien com los moleftos golpcs de fus mar- plican fer gemidos funerales los golpesflilos machacaba de continuo la cabeza del metal, de repente muda el afecto, y hr herrador vezino, quexòfe à la Jufticia, fe haze del vando de la laftima : afsi quéfl Abogado; 7 en virtud de fu privilegio, no la compoficion Mufica, fi los concep-pidiò fe expeliefe de la vezindad matraca. tos de la letra, efpccialmente quando fon an penóa, faliò à efte fin un auto del Juez, tan fagradas, fon la caufa de eftos movi- cuya notificacion refpondiò el herra-; mientos internos. \\ ‥ Con que importa poco todo el $\$$. 4. - Letrado, que yo prompto eltoi à quitar mi en que con'tanta furia perfigue V. R. lasherreria. Si cffos quicbros, effas inflexio- inflexiones, los quiebros, los Cromaticoshes, effos refvalones dulzes, que de un de vozes, ćrinftrumentos en las compofi-hunta d̀ otro inventò la raturaleza, y per- ciones modetnas. Bien sè yo, y aun meffionò el Arte, tuvieran las mifmas cir- atrevia d: citar la difpofiction del Santo unfancias, las mifmas qualidades, que Concilio de Trento,fobre cl modo de ufar n el theatro, y en el feftin, ferian abomi- de la'Mufica en la Iglefia; V: R. prefentchables, ferriun todas las maldiciones que. ticneadonde cae, reparela, hallarà pro- $\mathbf{Y}$. R. las echa, y en efte cafo ao cs teme-

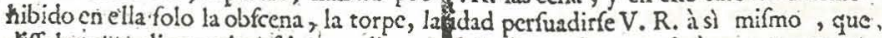 diffoluta $s$ y dignmoslo afsi ; aquella que dvirtiò, notò, $\$$ cenfurò mas que tantós

'Alrçobilpós, Obirpos, y perfonas zelofiffimas de la honra de la Cafa de Dios? ECfos Cromaticositiventǒlos's el Arte para figurarla voz, fin curyas figuras era imporfible hazêtlo perfectamente; fi à la noble tinvención de Juan de Múrs la faltara el 'generò Cromatico, de què firviera poder' ajuftar figuras a las filavas', fi fe quedaban inexplicables .los afeetos'? Qual que no fea duro, y defabrido fe pudiera ajuftar con folo el genero Diatonico 'Y ' $f: V . R$ mifmo alaba, como primor de la primera claffe, efta expreffion"de afectos, y effa es imporsible fin los fulftenidos", $y$ vemobles, como fe dexa caet en tan clara contradictoria con fu def́tịerro? Los Lacedemonios, y todos los Griegos en la rigurofa politica de fus Republicasfolian tropezar en la paja, y paffar port fobre la viga, y aun en lo fubftancial frouieron defatinos intolerables; quien fufriera la ridículez de un Filofofo morroñofo buifando hombres con linterna al medio dia ? Y quien to fe reiria mucho mas de vèr emperradón Epicuro en dezirle réquiebros â un dolor de muelas ? Efte genero de locuras paffe à quenta de lo que acertaton; pero authorizar con hechos tales las podri. das fentencias contra las cofas de eftos tiem. pos, muchos vifos tiene de dar en Filofo. fo de linterna. No niego yo tamposo la mayor fuavidad de efte genero mixto, $y$. que es mucho mas blanda la imprefsion que haze en la interno; niego empero effe defordenado alboroto de las pafsiones, al fon de una Guitarra, efpecialmente en humores bien templados, efte genero de Filofofia tengolo en romance, $y$ me es licita ufar de ella; he vilto un difcurfo admirable del modo con que auñ à la Medicina pudiera la Mufica abrirla los ojos;aquella proporcion de losva?os, donde los humores fe recogen, y la de las fibras, conque la naturaleza toca el orgąno de fus fenfaciones con los modos, y compafes muficos, bien sè como puede explicarfe, y con ella las alteraciones diferentes en el oyente; pero ni les concedo tan fuperior fuerza, y tiemblo de que en la duracion de mil figlos asabaffe la expzrienciz de affen- 
48

Sentar reglas fixas de proporcion entre los taniidos, $y$ afectos, entre los fones, y enfermedades ; en los mordidos de la tarantula es bien fabido fer ociofo qualquiera orro remedio, que la Mufica, pero en toda la eternidad accabarà de difinirfetañido, que thualmente provoque à baylar à todos los atárantulados; cfta impofsibilidad, a $\mathrm{mi}$ pácer, no nace fino de que fiendo difetentes los humores, y fu combinacion refpectiva en los pacientes, diverfa la mayor, o menor tenfion de fibras, y capazidad de vafos', neceffariamente requieren tañido, que impcla al hatre, con vibraciones proporcionadas al movimiento de vafos, y fipras ; y.por effo repoffa con el tańido un atárantulado, con que otro fe haze rajas àdanzar, yi efto mifmo es innegable cn los fauos, aque! afecto defpertarà a has alda. badas de la Mufica, que mas vezino eftuviere à las puettas de la proporcion, entre fus organos, y las confonancias, à muchos he vifto dormirfe en medio de un fuayifșimo concierto, y levantarfe otros, fin reparo al frio, los ecos de una farten raf$\therefore$

$\mathrm{Ca}-$

\section{0}

Francífco Palomino mas de mil latines rahè al affumpro, y yo no los quiero co. piar, porquie es tarde, y eftà para marchar el corré, ; fi quiere leerlos, no ferz̀ riempo perdido, porque la pariedad corre à quatro pies de las mifmas circunftancias. Que tiene quie vèr que en manos de un Idiota falga tras cada punto eftraño un puhal para el oido', con la bondad, ò maldad intrirífeca de los mifmos puntos? Condenefe à los que con ignorante audacip fe atreven à ufar de ellos, fin el primor dèl Arte, à los que metidos à Maeftros en la compoficion, ò en la execucion, no fon mas que digno objeto de vna lafți mola rifa, pero condenar el Arte, y no al profefrur, en defectos de que aquella vive immune, y efte lleno es confundir el orden de las cofas, y entendar fus entidades por el revès, y aun efte genero de ridiculas compoficiones pida la buena razon fe dexen paffar como tiznes de la facultad, fin zaherir ni à los que las execuin, ni à los que las componen. En miPatria c.sila celebrada Cal:a de Santiago llena fada, con que noes, ni puede fer general aquella imprefsion de imagenes confuffis, que nó reprefentan cofa bucna, y los defectos en efta parte neceflariamente eftàn en el recipiente; malo es que fa viciola la difpolicion interna, que ni toda la funefta melodia de un Milerere la harà volver atràs un punto. Ojala afsifuera! que mas de quatro converfiones hiv de lograr yo hazer, ý todos los de mi profefsion. Bien claro lo manifieftan las experiencias de tantos, cono al foplo de una pintura, por sì fantifsima, fe vèn abríar en infeliz fuego de fu tórpeza. Hanfe de borrar por eflo effas pinturas? Tan al contrario es, que ni aun aquellas, que fiendo profanas, llevan configo effe peligro, como no fea defde luego efcandalo de 1 s ojos , fe prohiben; pues en que lo pecó la Mufica, fiendo tan grande la diferencia de cáptar la vifta, ò el oido? Yo citàra lós verfecillos latinos, que lo prucban; pero Mufico me foi, y nada mas; mis razoncs las hallara bien eftendidas V.R. en las ofcritos del Apeles de nuctros tiempos Don Fan.

de Pintores, $y$ en ella mas de una vez ha renido bien que reprimirfe mi rifa de ver zurdo à San Geronimo,y una Vieja con un pimentero en la mano porCaftillo para dibuxar à.Santa Barbara, y ni por effo queman las pinturas, $\mathrm{y}$ los Pintores, $\mathrm{ni}$ dexan de venderfe à lo menos, para que firvan aquellas injurias del pincel contra la melancolia de un apofenro de mefon. Dexe V.R. effos Muficos, y Mufica para to mifmo, y confieffe comoen el $\$$. 5. que llenas de efios Cromaticos, y eftritos puntos falen oy infinitas obras excelentiffimas, capazes de hazer fombra à tocha la anyiguedad"; buenos teftigos fon las de D. Antonio (Literes, infigne Muffco, pero no $\tan$ unico, que repugne la compañia de un D. Joreph de Torres, de un Maétro S. Juan; de un Nebra, de un Scque:ra dulzifsimo; de un affombro del gufto, y la deftreza, Archangelo Coreli, de un Albinoni, profundifsin compoticiones; de un Vibaldi; celcbrado de todo exccutor de bucn gufo, cuyas extravagancias dizen bien los cfealunes 
que fubiò de primor en efte genero de compoficion ; yen fin en efta Univerfidad tenemos al Scopor Doctor Don Antonio Yanguas Catheuratico de Mufica de ella, cayar obras harian fin duda $a v, R$, def dezirfe gufiofo de fu dictamen. Todos eftos componen, y har compuefto para los Templos acertadísimamente; $; y$ del ulti móhe oido un Míferere, y un Benedictus. en Jas Tinieblas del Jueves Santo, tales que pucdanalumbrar à la noche mas Critica, fumamente dulzes, fumamente graves, $y$ agradablemente ferios, de modo. que con qualquiera obra de tąlés fúgetos que oyefe $V$, $R$, haria mas merced no folo à la Elpañola feriedad, que por $I_{3}$ mifecicordia de Dlos años haze que firve de algo más, que de ir embarada en dos mil botones de calzon, y ropilla., y ajurtado el gaznate en un zepo de carton pos effis Calles, fino tambien a la noble Ita. lia, quien aun entre las ruinas que le causò el diluvio de Barbarie, que fobre ella cayò; muefrabien, que en fu regazo fe arrullaron; $y$ : criaron las ciencias todas,

otros que la hizièron quartos ,y à effor jos que la dividieron en minutos, def, pues de los quales los de rueftros tiempos han hallado medio de reducirla à fegundos, y con ellos contarnos las pulfadas de una arteria ; y efto es arguménto de eftar perdida la Reloxeria? En las mas compoliciónes no fon neceffarias las tricorcheas. ni quatricortcheas; pero ni taŕf́ócó en el regularufo de los Reloẍes fe necefsita effa inperceptible precifsion de fegunidos, y terceros; y pó effo es condenable tan curiofa invencion ? Sea ; ò no hiperbolica la figuracion del canto del Rui-Señor que hizo el P: Anaftafio Kirker, lo cierto (s), que fin las quatricorćtieas no huviera podido explicarla fegun la concibiò ; fua pongo cue tierien'eftas por lo regular pocoluto 's peto fi las tricorcheas faltaffer en los adagios patheticos $;$ 'cuyo compàs por finaturaleza es una nitad mas grave que el compafillo regular, explicariamos las gloffà cón fem:corchizs ? Efià es la razen kadre mio de que en un compas quefa tap crecida pumero de figuras; y de
G à efte paffo fon cada dia fus partos èn todas ellas.

Buenas prucbas fon las del naufragio de la Mufica en nueftros tiempos; en la antigua critica reglaba fus aprehenfiones el entendimiento en las valanzas del juicio, hafta que las facaba cabales difcurfos, y fentencias loables; la de oy parceeme que haze todo lo contrario; el entendimiento enredacior, y perperuo faltinbanqui déxa dornir el dif́curío, y efcurriendofe bonicamente, hurta las valanzas al juicio,y huelgafe à peffar aprehenfiones;y la de fu gufto, fi le fale efcafa',añadela hierro, hafta ponerla en el fiel de fu capricho. Apenas fe podrà efto verificar, mejor que en la pretenfion de eftar perdida la Mulica por la diminucion de figuras. No vè $P$. Rmo. que fuera error intoletable conde. nat̀ à lós Reloxeros, porque con futilifsitho primor han obligado à efta bella maquina à que nos quente el tiempo po: inftrntes? Vivicron los antiguos muy contentos de haver hallado por efte medio la divission horaria del tiempo ; fusedieron'c otres que un executor habil pucda hazer inflexion, variacion, $y$ faltos fin violencia ; y no fue la contraria la que privò al P. Kirker,de oir bien executadas fus compoficiones, fino que efte, $y$ otros infignes Math ematicos las regulan fin refpero alguno, à vozés, ò inftrumentos; por foIo las reglas meramente Theoricas de proporcioti harmonica; $y$ afsi falen innexecutables, porque fon verdaceramente exoticas en lo practico. Conozci à cierto Cavalleto eri cfta Univerfidad, que llcvado de fu grafidifsima deftreza en cfta, y otras mayores Ciencias; hizo una femejante compoficion; y haviendola moftrado al Cathedratico, entónces de $\mathrm{Mufica}_{2}$ le refpondiò: eftà admirable; lleña de proáigios harmonicos, pero fi Vind.no la eńtrega à los Angeles, quedarafe fin oir$\mathrm{fa}_{\mathrm{a}}$ : aîsi, que no fon eftás compoficiones para citadas à favor de la imporsibilidad en la cxecucion. Las que V. R. parece quicte no fe imoriman, ni dexen, youar por effas Provincias, for aquellas que fiendo executables, llevan copfigo tódo cl gol. 
25

golpe de di dificulad en lo practico; bue na razon, necéfario era, fegun ella, quemar las ipoliticas de los Fulofofos, y las defcripciones de hombres perfectos, que har hecho los Poetas; moralmente fon in: capazes de reducirfe a practica, y por effo. han de rafgarfe tales obras ? Dexelas $V_{i}$ R. couret i, Y luzir, para credito de fus Authores para prueba de que no fe duermen los prefentes en,comparácion de los paffados y finalmente, para que en ellas étudien los ingenios prímorofos, y firvan deóriginales a una anfiora, imitacion, dé cito firven los liénzos de lós mas celebrados, Pintores, y en cllos eftudian los quiz no fon como Orbaheja el deUbéda, que pinzaba lo que falia, y el que logra verlas co maños de un Séminiani, y de un Gaj biricl, quecda empehado en allakir á Dios que tales habilidades da a fus criaturas. Yo se que.fi V.'R. lolografte, no fe que' xaria de que no le hazian ímprefsion en clokdo la muchedunbre, y breyedad de tanto punto cr un compàs menos, que tuvielfe por timpano en cịna baquéta
‥

de Mof́cbbia. Si otros de menos habilidad arañan eflas obras, y de una tan bue: na melodia hazen una trapala confura, dexelos, que à Dios daràn la quenta; y por primer partida de data la rifa de los intes ligentes, en fin ellps comen de fui trabajo, $y$ viven de fu fudor, cumpliendo afsi la mas antigua multa del mundo, en lo que por mi los abfuelvo de rodo pecado.

No quiero volverme à acordar del ufo de los tres generos Diatonico, Cromatico, y Enarmonico, porque và largo, el muchacho me eftà acordando à cabezadas fobre el brafero el peligro de cerrarfe la eftafeta ; pero fi del reftimonio, que fe le levanta à la Mufica moderna, de que en ella no fe figien paffos. Confulte Padre las obras, que arriba citè, y efpecialmente la quinta, y fexta de Coreli, y todas las de Albinoni, y fe hallarà defengañado con: tales conciertos, y el que en toda Simpho-1 nia no fuceda lo mifmo, pende de otro. principio, que explicaria yo, fi difcurriera que V. R. havia de entenderlo; pero a quiere faber como fe fragua eftos cn laC

yos?

\section{.}

\section{8}

i vos; metafe à Hermero, $y$ fino pacienciaj que ni yo, niEftrangero alguno de quanto\$ vienen à Efpaña eftamos por aora en obli-: gacion de manifeftarle quanta mayor dificultad tiene effa;, que llama Mufica fuelta, y defgreñada, que la atada à las argollas de quatro puntós gordos. En efta fuè infigne Duròn; y jamàs pudo llegar à poffeer aquella; porque eftaba yà viejo Pedfroe. X: nó fueta pequeña gloriafuya haver intro. ducidoen Ef pana efte genero de compofi. cion ; ; pero fir Durón refucitàra y nafufriera. fu modeftia tal teftimonio. Pafsòme por Sobre el $\$:, 9 . y$ ro, que eftàn, xa bieu fatisfechos, y la difcordia de los fapientifsimos KirKer; y Dechales, es. una de laș pruebas de que no en todos caufan las mifruas confonancias, , aquellas imagenes confiras; que no reprefentan coĺa buena.? Tambien fobrefeo à la diferencia accidental de los tonos, fu mayor, ó menor al totra , ò agưdeza y fi bien noto, que para mi à lo" inenos es impofsible entender, que gertero de tónos fon los que violentan tanto la voz s que le quitan la facilidad de fu

(n) 
la que $V$. R. hizo fabricar con fexta of: den, y firviò folo fu abultada caxa para molde de cunas) eftando dividida, contra todo el rigor harmonico, en doze partes iguales, fru Diapasòn, y lo mifmo digo de los Organos regulares, Harpas, Laudes, - Citaras, \&ce. por fu defajuftada divifion: con que por efta parte tengo à mi Violin por fuperior à todos los demàs inftrumentos. Que importa fi fus chillidos fon infoportables? $y$ infunden en nofotros una vi:veza pueril? Mui delicados fon los timpanos.de Jos oldos de V.R.ò mui ligera tiene Ja:fangre ; tales feràn las manos, que los manejan y quando ellos chillan con tanta furia:Bl executor dieftro en puntos tan altos, fabe afloxar el arco,y manejarle con tall fuavidad, que parece entonces no Violin , fino una dulzirsima flautilla, con lo quelogra una melodia mui fuperior, aun à la que maneja, fin trafportar la mano, y aun quando le apriete a todo peffo de arco, feràn viivas; pero no moleftas fuis confonancias, la cortedad de la cuerda, ny la imperceptibilidad de fus menudas bi-
- 32 braciones mueven menos alre fin duda de lo que es menefter para defcalabrar orejas, y es buena razon quererle defterrar como inutil por lo poco que importa que falten tiples en la Mufica inftrumental, y que hemos de hazer del Obuè,del Clarin, de la Chirimia, de la Corneta, y aun de las Nazardas , y Ranillas de los Organos. Baxifsima Mufica havia de quedar, P. R. bravamente fonaria à bodega, y de lostales tiples es fonora la dulçura del Obuè, la valentia de un Clarin, y la harmonia de tạn menudas flautillas, pero puede $V$. $R$. fufrir la horrible gregueria de una Chirimia, y los defefperados ahullidos de una Corneta, que apenas hai fin ellas Capilla Mufica, y enfadanle los Violines? Si à todos nos quiere defterrar de la Iglefia, portiples, y por gritadores, contra la comun aceptacion, y ufo, no de un Pueblo, fino de tantos Reynos, y Provincias, y lo que es mas, de la mifma Roma,en donde Mufica Moderna, Clarines, Violines, y Obuès, y todos los demàs inftrumentos fe oyen, fe tañen, y fe aplauclen à vifta de

\section{2}

la Cabeza mirna de la Iglefia ; verdadera: mente que es punto arduo.

$\mathrm{Si}_{\mathrm{i}}$ en eftos renglones fe huviere def: lizado la pluma, creame V.R. que no llevo la mas minima intencion de ofenderle; refpeto, venero, y alabo fu univerfal inte. ligencia en todas materias, fu authoridad, fus prendas, fu Santifsimo Habito , y fu nacimiento, $y$ à efta proporcion defeo que no me ponga en el numero de los Zoilos defcocados, de los que muerden la piedra, no la mano, efto es al Author, no à la fenrencia, fi no en el de los que defean eftudiar, $y$ aprehender, exercitandofe en la efcuela de la gran habilidad de V. R. à quien ofrezco ( fi guftare advertirme mis yerros) un tratadito largo de las ventajas de la Mufica moderna à la antigua, $y$ del Violin à todos los demas Im?trumentos; y en el interin fervirle cö finifsima voluntad en quanto difcurrieffe provechofa mi inurilidad.Dios guarde àV.Rma.muchos ańos, Salamanca is 14 de Diziembre de 1726.

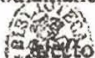

